\title{
EL FORUM SHOPPING Y LA LEGISLACIÓN CHILENA SOBRE ACCIÓN COLECTIVA DE ACREEDORES
}

[Forum Shopping and Chilean legislation about creditor collective action]

\author{
Nicolás Carrasco Delgado* \\ Universidad de Chile y Universidad Autónoma de Madrid
}

\begin{abstract}
RESUMEN
En este trabajo exploraremos el fenómeno del forum shopping en una perspectiva propiamente procesal. Habitualmente se lo ha vinculado con la opción que tienen los litigantes de elegir el tribunal al cual acudir, en términos tales, que preferirán el tribunal que resuelva de mejor manera sus intereses. Sin embargo, en ciertos supuestos es posible extender el concepto de forum shopping no solo a la elección del tribunal sino que también a una elección procedimental. Ello sucede cuando estamos en presencia de una acción colectiva de acreedores, esto es, cuando existen múltiples sujetos que
\end{abstract}

\begin{abstract}
In this work, we will explore the phenomenon of forum shopping strictly from the perspective of procedural law. It has normally been associated with the option available to litigants to choose a court to resort to, in such a manner that they will prefer the court which resolves best serves their interests. However, under certain assumptions, the concept of forum shopping can be extended not only to the choice of court but also to choice of legal proceedings. This occurs in the presence of collective action on the part of creditors, i.e. when there are multiple subjects with credit rights over a common debtor. Under such
\end{abstract}

ReCiBido el 1 de julio y APROBADO el 1 de diciembre de 2016

* Profesor Asistente Derecho Procesal Universidad de Chile. Abogado. Licenciado en Ciencias Jurídicas y Sociales y Magíster con mención en Derecho Económico, Universidad de Chile. Doctorando en Universidad Autónoma de Madrid. Becario Becas Chile para Estudios de Doctorado en el Extranjero. Dirección postal: Pío Nono 1, Santiago, Chile. Email: ncarrascod@gmail.com. 
poseen derechos crediticios en contra de un deudor común. En tal supuesto, los acreedores poseen diferentes vías procedimentales a las cuales recurrir (procedimientos individuales de cobro y procedimientos colectivos concursales). Se tratará de indagar las opciones de elección para los acreedores y el deudor entre tales vías procedimentales en la legislación chilena desde una perspectiva de eficiencia e incentivos.

\section{PaLABRas Clave}

Concurso de acreedores-InsolvenciaDerecho Procesal- Análisis Económico del Derecho. an assumption, the creditors enjoy different legal avenues to which they may resort (individual debt recovery proceedings and collective insolvency proceedings). We will seek to investigate the choices available to creditors and debtors between such legal avenues in Chilean legislation from the perspectives of efficiency and incentive.

\section{KeYWORDS}

Creditors concurrence- Insolvency - Procedural law - Law and economics.

\section{EL FENÓMENO DEL FORUM SHOPPING Y LA ACCIÓN COLECTIVA DE LOS ACREEDORES**}

En esta primera sección examinaremos los conceptos básicos a desarrollar en este artículo: la idea del forum shopping y la idea de la acción colectiva de los acreedores. De esta forma, centraremos el tratamiento de las secciones sucesivas en la bondad o desventajas de la elección del demandante respecto del procedimiento por medio del cual llevar a cabo el cobro de sus acreencias.

\section{El fenómeno del forum shopping}

El forum shopping ha tenido un tratamiento amplio en la literatura jurídica comparada ${ }^{1}$. La doctrina ha dedicado múltiples trabajos a delimitar

** Abreviaturas: LREP (= Ley N o 20.720 de Reorganización y Liquidación de Empresas y Personas)

${ }^{1}$ Puede verse: BASSETT, Debra, The Forum Game. en North Carolina Law Review 84 (2006), pp. 334-396; Norwood, Kimberly, Shopping for a Venue: The Need for More Limits on Choice, en University of Miami Law Review 50 (1996), pp. 267334; LoPucki, Lynn y WhITFOrd, William, Venue Choice and Forum Shopping in the Bankruptcy Reorganization of Large, Publicly Held Companies, en Wisconsin Law Review 11 (1991), pp. 11-63; MaIER, Harold y Mccor, Thomas, A Unifying Theory for Judicial Jurisdiction and Choice of Law, en The American Journal of Comparative Law 39 (1991) 2, pp. 249-292; BAXTER, William, Choice of Law and the Federal System, en Stanford Law Review 16 (1963) 1, pp. 1-42, y BaIRD, Douglas y JaCKSON, Thomas, Corporate Reorganization and the Treatment of Diverse Ownership Interests: 
su concepto, sus implicancias, beneficios ${ }^{2}$ y desventajas ${ }^{3}$. Especial énfasis ha recibido en el derecho norteamericano, donde por la estructura de su sistema judicial ${ }^{4}$, se ha hablado del forum shopping vertical (aplicable a la elección entre tribunales federales y estatales) y forum shopping horizontal (aplicable a la elección entre tribunales estatales), recibiendo un tratamiento benigno el segundo, mas no, el primero5. También ha sido materia desarrollado en el derecho internacional privado donde la elección del foro para el conocimiento y resolución de conflictos multinacionales constituye un asunto habitual ${ }^{6}$.

Una apropiada conceptualización de este fenómeno fue realizada por el Tribunal de Rimini, por resolución de 26 de noviembre de $2002^{7}$, que lo define como "La actividad que persigue alcanzar la más favorable jurisdicción para los intereses del demandante". Tal definición resulta adecuada dada su

A Comment on Adequate Protection of Secured Creditors in Bankruptcy, en University of Chicago Law Review 51 (1984), pp. 97-130.

${ }^{2}$ En una posición favorable al fenómeno del forum shopping, puede verse: ALGero, Mary, In Defense of Forum Shopping: A Realistic Look at Selecting a Venue, en Nebraska Law Review 78 (1999) 1, pp. 79-112; Clermont, Kevin y EisenberG, Theodore, Exorcising the Evil of Forum-Shopping, en Cornell Law Review 80 (1995) 6, pp. 1507- 1535; LundQuist, Weyman, The New Art of Forum Shopping, en Litigation 11 (1985) 3, pp. 21-59.

${ }^{3}$ En una posición crítica al fenómeno: Norwood, Kimberly, cit. (n. 1); HaRvard Law Review, Note: Forum Shopping Reconsidered, en Harvad Law Review 103 (1990) 7, pp. 1677-1696, y Corr, John, Thoughts on the Vitality of Erie, en The American University Law Review 41 (1992), pp. 1087-1137.

${ }^{4}$ Puede verse: Marcus, Richard, Conflicts Among Circuits and Transfers Within the Federal Judicial System, en The Yale Law Journal 93 (1984), pp. 677-721; CuRRIVAN, John, Choice of Law in Federal Court After Transfer of Venue, en Cornell Law Review 63 (1977) 1, pp. 149-163, y Clermont, Kevin, Restating Territorial Jurisdiction and Venue for State and Federal Courts, en Cornell Law Review 66 (1981) 3, pp. 411-463.

${ }^{5}$ Ferrari, Franco, Forum Shopping in the International Commercial Arbitration Context: Setting the Stage, en FERRARI, Franco (Editor), Forum Shopping in the International Commercial Arbitration Context (New York, Sellier European Law Publishers, 2013), pp. 15-16.

${ }^{6}$ Puede verse: Chemerinsky, Erwin, Assessing Minimum Contacts: A Reply to Professors Cameron and Johnson, en UC Davis Law Review 28 (1995), pp. 863-870; Simowitz, Aaron, A U.S Perspective on Forum Shopping, Ethical Obligations, and International Commercial Arbitration, en FerRari, Franco (Editor), Forum Shopping in the International Commercial Arbitration Context (New York, Sellier European Law Publishers, 2013), pp. 23-52, y STernberg, Daniel, Res Judicata and Forum Non Conveniens in International Litigation, en Cornell International Law Journal 46 (2003), pp. 191-218;

${ }^{7}$ [visible en internet: http://cisgw3.law.pace.edu/cases/021126i3.html]. 
neutralidad, toda vez que, la misma solamente exige que el demandante considere la elección más favorable a su posición, sin exigir que adquiera una ventaja sustantiva ni que la elección sea correcta considerando los factores relevantes. A partir de esa conceptualización, se aprecia que en materia del forum shopping existe una tensión procesal evidente. Por una parte, el interés del demandante de elegir el tribunal o el procedimiento más adecuado a sus intereses, y por la otra, el interés del sistema procesal, en cuanto sus órganos jurisdiccionales e instrumentos procesales no sean utilizados para fines de obtención de alguna ventaja indebida.

En este sentido, por ejemplo, se encuentra el surgimiento del forum non conveniens, según la cual se busca limitar el fenómeno del forum shopping en la medida que el demandado demuestre que existe otro tribunal que puede resolver el asunto de manera más conveniente para el interés de las partes y las exigencias de la justicia ${ }^{8}$. De esta forma, si bien se reconoce el derecho del demandante de poder elegir el foro que se acomode a sus intereses, ello no ocurrirá cuando su actuar vulnere las exigencias de justicia.

Ahora bien, el fenómeno que se estudia ha sido examinado desde la perspectiva de la elección del tribunal que debe conocer del asunto. No obstante ello, quisiera extender el análisis a lo que denominaré forum shopping procedimental, que refiere la elección del demandante del procedimiento que más le acomoda en el contexto de la acción colectiva de los acreedores, esto es, de aquellas situaciones que se generan por la existencia de un deudor con múltiples acreedores ${ }^{9}$. Explicando este fenómeno, Baird señala que los incentivos de dos acreedores (un banco y un trabajador) para elegir un tribunal dependerá de cuál tribunal resuelva más cercano a sus intereses ${ }^{10}$. De esta forma, las instituciones bancarias concurrirán al tribunal que decida consistentemente a favor de tales instituciones, y lo mismo ocurrirá con los trabajadores.

Tal ejemplo detalla el supuesto normal del fenómeno que se analiza desde la perspectiva de la elección de un tribunal determinado. Sin embargo, la existencia de distintos procedimientos para afrontar un mismo tipo de conflicto también genera lo que ha denominado como forum shopping.

${ }^{8}$ Por ejemplo, el artículo 28 U.S.C \& 1440 (a) (1988): "For the convenience of parties and witnesses, in the interest of justice, a district court may transfer any civil action to any other district or division where it might have been brought". (Trad. del autor: "Por la conveniencia de las partes y los testigos, en el interés de la justicia, un tribunal de distrito puede transferir cualquier acción civil a cualquier otro distrito o división donde hayan sido iniciada").

${ }^{9}$ Ferrari, Franco, cit. (n. 5), p. 9.

${ }^{10}$ BaIrd, Douglas, Loss Distribution, Forum Shopping, and Bankruptcy: A Reply to Warren, en The University of Chicago Law Review 54 (1987), p. 826. 
Un ejemplo, en este sentido es cuando nos encontramos en presencia de incumplimientos del deudor. En tales circunstancias las legislaciones contemplan distintas vías para hacer frente a un deudor común con varios acreedores ${ }^{11}$. Baird indaga las razones por las cuales existen tales alternativas múltiples en materia de incumplimiento de deudor ${ }^{12}$. La pregunta surge porque el hecho de contemplar distintas soluciones procedimentales supone un costo, debiendo existir una justificación al mismo. Baird responde que el motivo para agregar un procedimiento concursal se debe a la necesidad de resolver un problema de acción colectiva que surge entre las variadas clases de intervinientes que participan en tal procedimiento ${ }^{13}$, buscando que los acreedores puedan coordinar su comportamiento ${ }^{14}$.

Ahora bien, la existencia de tales alternativas supone que no todas las situaciones de incumplimientos de pagos donde concurran varios acreedores con un solo deudor generarán procedimientos colectivos, siendo posible que incluso ni siquiera se judicialice el conflicto $^{15}$. La razón para ello se encuentra en que los acreedores y deudores elegirán la alternativa que satisfaga de mejor manera sus intereses, por ejemplo, el procedimiento concursal puede establecer privilegios a ciertos acreedores que no se reconocen en una ejecución individual, en ese caso el acreedor que mejora su preferencia de pago con tal privilegio optará por la vía concursal; o bien, si un acreedor considera que la manera en interpretar la ley en los procedimientos ejecutivos individuales se acerca a su posición, entonces, optará por tales procedimientos una vez planteada la situación de no pago.

\section{LA ACCIÓN COLECTIVA DE LOS ACREEDORES}

El problema de la acción colectiva de los acreedores ${ }^{16}$, refiere la exis-

${ }^{11}$ BAIRD, Douglas, cit. (n. 10), p. 824: "The challenge facing anyone who wants to write about bankruptcy policy is to explain why a distinct bankruptcy law exists at all. Introducing multiples avenues of enforcement is costly". (Traducción del autor: "El reto para cualquiera que quiera escribir acerca de políticas de bancarrota será explicar el por qué existe una ley de bancarrota diferenciada. Introducir múltiples vías de ejecución es costoso").

${ }^{12}$ En este sentido, indaga razones de reducción de costos (por ejemplo, reducir los costos de litigar entre ciudades lejanas estableciendo un tribunal en cada ciudad); de creación de estatutos sustantivos especiales, y de protección del principio de prioridad absoluta de los acreedores. Véase: BAIRD, Douglas, cit. (n.10), pp. 825-831.

13 Barrd, Douglas, cit. (n.10), pp. 827-830.

${ }^{14}$ Baird, Douglas, cit. (n.10), p. 819.

15 BaIRD, Douglas, cit. (n.10), pp. 816-817.

${ }^{16}$ JACKSON, Thomas, The logic and Limits of Bankruptcy Law (Cambridge, Harvard University Press, 1986), pp. 8-12. 
tencia de múltiples acreedores (todos con intereses distintos) enfrentados a un deudor común. En tal escenario Jackson señala que las soluciones de tutela individual son completamente ineficientes y conducen a resultados socialmente indeseados. En efecto, tales ejecuciones individuales presentarán problemas de externalidades negativas respecto de los acreedores y del deudor. En relación a los acreedores se origina el problema del common pool y que se grafica en la idea de que frente a un recurso común sus distintos titulares -siempre que no deban comportarse como grupo- actuarán depravando el recurso, aun cuando ello no satisfaga la maximización del recurso en el mediano y largo plazo, pero sí en el corto plazo. Tal alternativa se transforma en la más racional para los acreedores, al no poder controlar la actividad de los otros titulares, quienes actuando en su puro interés personal también extraerán lo máximo que puedan ${ }^{17}$. Por su parte, la externalidad negativa respecto del deudor, nos remite al desmembramiento inorgánico de sus activos en virtud de múltiples ejecuciones individuales paralelas o sucesivas ${ }^{18}$.

Asimismo, Jackson grafica que los acreedores se encuentran inmersos en un juego de cooperación de múltiples partes, en donde las soluciones individuales son contradictorias con el objetivo de beneficiar a todos los acreedores como grupo ${ }^{19}$. De esta forma, parte de la dificultad es que el procedimiento concursal trata a los acreedores como grupo, en circunstancias que ellos provienen de un mundo donde tenían a su disposición mecanismos individuales de satisfacción crediticia ${ }^{20}$. Tal c o l e c t i v i z a c i ó n desde una lógica inicialmente individual, puede originar diferencias entre los acreedores ${ }^{21}$. En efecto, es posible que en los procedimientos

${ }^{17}$ JaCKSOn, Thomas, The Logic and Limits of Bankruptcy Law, en Discussion Paper Program in Law and Economics Harvard Law School, 16 (1985), pp. 13-15. El autor grafica la idea del common pool en el caso de la extracción de peces de un largo, indicando que la actuación de sus titulares basada en el interés personal terminará agotando el recurso en el corto plazo.

${ }^{18}$ En este sentido, Posner, Richard, El análisis económico del Derecho (1a edición, México, DF, Fondo de Cultura Económica, 1992), pp. 380-381, nos señala: "En tal mundo (en donde no exista ley de quiebras con un principio de igualdad), cada acreedor tendría incentivos para ser el primero en obtener un fallo judicial contra el quebrado, y la carrera tenderá a privar a la compañía de sus activos con mucha rapidez para maximizar el valor de tales activos". En este mismo sentido, y recalcando el hecho que el desasimiento produce una coordinación en la actuación ejecutiva de los acreedores que impide la destrucción irracional y parcial del activo del deudor: WohlsChlegel, Ansgar, The Economics of Corporate Bankruptcy Law, p. 9 [visible en internet: archiv.ub.uniheidelberg.de/savifadok/volltexte/.../Diss_Wohlschlegel.pdf].

${ }^{19}$ JACKSON, Thomas, cit. (n.17), p.12.

${ }^{20}$ JACKSON, Thomas, cit. (n.17), p. 26.

${ }^{21}$ JACKSON, Thomas, cit. (n.17), pp. 35-37. 
concursales se produzcan violaciones a la regla de prioridad absoluta de los acreedores ${ }^{22}$, esto es, al orden de preferencia en el pago de los créditos. Si eso es así, entonces, surgirán conflictos entre acreedores privilegiados (quienes querrán conservar el derecho a un pago preferente) y acreedores valistas (quienes intentarán forzar una violación a la prioridad absoluta) ${ }^{23}$. Asimismo, pueden ocurrir situaciones de acreedores obstructores, esto es, acreedores que solicitan el inicio de un procedimiento concursal a pesar que el resto busca una salida negociada con el deudor ${ }^{24}$. Por último, en el caso que el procedimiento concursal establezca un tratamiento al problema de la acción colectiva de los acreedores diferente del otorgado por la tutela individual común, entonces, surgirá un incentivo para que los acreedores beneficiados con ese disímil tratamiento opten con la vía concursal a fin de extraer tales beneficios ${ }^{25}$. Tal incentivo entrará en colisión con aquellos acreedores perjudicados por el tratamiento diferenciado. Más aún, esas diferencias surgen si el concurso corresponde a una alternativa predominante respecto de la ejecución individual. Tal dominancia se demuestra en el hecho que el concurso normalmente supone la paralización o suspensión de tales ejecuciones y su sometimiento al foro común del concurso ${ }^{26}$.

\section{LA EXTENSIÓN DEL CONCEPTO DEL FORUM SHOPPING}

DESDE UNA PERSPECTIVA PROCEDIMENTAL: EL CASO DE LOS

INSTRUMENTOS DE COBRO INDIVIDUALES Y COLECTIVOS

\section{La extensión del forum shopping procedimental}

Se ha sostenido como apoyo del carácter sustancial de los procedimien-

22 Puede verse: Hart, Oliver, Firms, Contract and Financial Structure (1 $1^{\mathrm{a}}$ edición, Oxford, Claredon Press, 1995), pp. 105-107; CARAPETO, Maria, Is bargaing in Chapter 11 costly?, en Working Paper, London City University Business School (2000), pp. 24-25, y BeвChUсK, Lucian y Fried, Jesse, A New Approach to Valuing Secured Claim in Bankruptcy, en Harvad Law Review 114 (2011), pp. 2386-2436.

${ }^{23}$ Warren, Elizabeth, Bankruptcy Policy, en The University of Chicago Law Review 54 (1987) 3, p. 804.

${ }^{24}$ GoldenberG, Juan Luis, Los acuerdos extrajudiciales desde la visión privatista del derecho concursal, en Revista de Derecho de la Pontificia Universidad Católica de Valparaiso XLII (2014), pp. 218-219.

${ }_{25}$ BAIRD, Douglas, cit. (n. 10), pp. 832-833.

${ }^{26}$ En el derecho procesal concursal chileno se consagra el suspensivo respecto de todos los procedimientos que pudieran afectar la situación patrimonial del deudor. En este sentido, el artículo 57 inciso $1 \mathrm{~N}$ o 1 letra b) LREP, establece tal efecto respecto de la resolución que declara el inicio de un procedimiento concursal de reorganización. Asimismo, el artículo 135 LREP, regula esa materia en la resolución que da inicio al procedimiento concursal de liquidación. 
tos concursales, la supuesta existencia de un e $\mathrm{s} \mathrm{t}$ a d o d e $\mathrm{q}$ u i e b r a , que sería independiente de los procedimientos concursales. Tal estado existiría con anterioridad a la resolución que declara el inicio del concurso en razón de la conexión ineludible entre esa resolución y sus presupuestos sustanciales. La cuestión, entonces, supone resolver si concurre esa conexión ineludible. En caso que respondamos a tal interrogante de manera afirmativa, entonces, tendremos que sostener la existencia de un e $\mathrm{s} \mathrm{t}$ a $\mathrm{d}$ o c o n c u r s a l de naturaleza sustantiva que pre-configuraría el derecho de la insolvencia. Con todo, veremos que tal conexión ineludible no existe. En efecto, en la generalidad de los sistemas jurídicos concurre la ejecución individual y la ejecución colectiva ${ }^{27}$. Lo que implica la reunión de los acreedores en el patrimonio del deudor de manera separada e independiente (ejecución individual), o bien, de manera conjunta como un grupo en una comunidad de beneficios y pérdidas (ejecución colectiva) ${ }^{28}$.

Ahora bien, adentrándonos en la respuesta a la pregunta propuesta, podemos afirmar que no existe estado de cosas de déficit patrimonial, cesación de pago, o insolvencia que configure lo que se ha denominado como un e s t a d o c o n c u r s a l, sin que exista una homologación jurisdiccional de los presupuestos objetivos de inicio del concurso. Por lo mismo, el e s t a d o c o n c u r s a l solo existirá cuando una resolución declare la apertura de un procedimiento concursal. La explicación para ello es sencilla: Incluso existiendo causal legal que habilite alguno de esos procedimientos, como sería la cesación de pagos en la legislación chilena; la insolvencia en la normativa española, o la incapacidad de pago actual o inminente en Alemania, es probable que nunca llegue a existir procedimiento concursal. Lo anterior, porque las legislaciones contemplan remedios judiciales no solamente vinculados con la universalización del concurso, sino que también, relacionados con sistemas de ejecución individual. Por tanto, y a falta de regla que mandate proceder necesariamente por un procedimiento concursal, el acreedor será libre de optar -en presencia de cesación de pagos, insolvencia o incapacidad de pago actual o inminente-, por el juicio individual o por el juicio concursal. Y para el supuesto que ninguno de los acreedores opte por el último, entonces, no tendremos concurso. A ello debemos agregar los incentivos para el deudor de apertura

${ }^{27}$ Sobre la existencia de una regulación referida a la ejecución individual como alternativa universal y abstracta al juicio colectivo universal, puede verse: JACKSON, Thomas, cit. (n.17), pp. 9-10.

${ }^{28}$ Pérez Ragone, Álvaro, Prelación, isonomía y agrupamiento de créditos en la ejecución civil, en Revista de Derecho de la Pontificia Universidad Católica de Valparaíso XXXVII (2011), p. 447. 
del concurso, que existen en el derecho comparado ${ }^{29}$ y en Chile ${ }^{30}$, y que no concurre en la ejecución individual. Ello amplía los ámbitos del concurso.

2. La legislación chilena y las distintas vías procedimentales de cobro como expresión del forum shopping procedimental

El derecho chileno es un ejemplo de un sistema jurídico donde posee presencia el fenómeno del forum shopping procedimental. Para demostrar lo anterior supondremos un ejemplo muy sencillo. Un deudor (deudor: D) solicita un préstamo a una institución bancaria (acreedor 1: $\left.A_{1}\right)$ por $\$$ 100 , y a una persona natural (acreedor 2: $A_{2}$ ), por $\$ 200$. Tal préstamo es solicitado a $A_{1}$ en un momento inicial (al que denominaremos: $T_{1}$ ), para luego solicitar el préstamo a $\mathrm{A}_{2}$ (momento al que denominaremos: $\mathrm{T}_{2}$ ). Ambos préstamos deben ser pagados en un momento posterior (que corresponde a: $T_{3}$ ). En el caso del préstamo con $A_{1}$ el mismo se suscribió por medio de un pagaré y en el caso con $\mathrm{A}_{2}$ por medio de un contrato de mutuo. Llegado $\mathrm{T}_{3}$, D solamente paga $\$ 50$ a ambos acreedores. Por lo tanto, $A_{1}$ y $A_{2}$ deben decidir si demandar o no a $\mathrm{D}$. Al momento de adoptar esa decisión ellos apreciarán que el sistema jurídico chileno les permite múltiples vías de cobro.

Respecto de $A_{1}$, posee a su disposición a lo menos 3 vías de cobro: $i$ ) Un procedimiento ejecutivo; ii) Un juicio ordinario de cobro de pesos, y iii) Un procedimiento concursal. Las vías i) y ii) son mecanismos de tutela del crédito de carácter individual, mientras que en el caso iii) se trata de una vía procedimental colectiva. En relación a $\mathrm{A}_{2}$, sus vías principales de cobro son 2 con una tercera eventual. En este sentido, $A_{2}$ tiene a su disposición los procedimientos indicados en las letras ii) y iii) anteriores. Eventualmente podría acceder a la vía indicada en la letra i) precedente, si es que obtiene un resultado favorable en una gestión preparatoria de la vía ejecutiva.

Ahora bien, la legislación nacional no posee una preferencia normativa por alguna de las vías de tutela individual (lo que incluye tanto el procedimiento ejecutivo como el ordinario). Sin embargo, contempla un desincentivo para dar inicio a los mecanismos colectivos de persecución de acreencias (procedimientos concursales), ya que respecto de estos

${ }^{29}$ Por ejemplo en la legislación concursal española el artículo 2 párrafo 3 de la Ley 22/2003, de 9 de julio, Concursal.

${ }^{30}$ En efecto, en el derecho procesal concursal chileno el deudor es un sujeto legitimado para dar inicio a gran parte de los procedimientos concursales. Así se establece en el artículo 54 inciso $2 L R E P$ respecto del procedimiento concursal de reorganización judicial; en el artículo $102 L R E P$, respecto del procedimiento concursal de reorganización extrajudicial o simplificado, y en el artículo 115 LREP. 
últimos existen ciertos desembolsos que no son exigidos en las vías procedimentales de tutela individual. Por ejemplo, la consignación de 100 Unidades de Fomento como requisito de admisibilidad de una demanda de liquidación forzada.

Es interesante analizar esta materia a la luz de los procedimientos concursales. La Ley N o 20.720 de Reorganización y Liquidación de Empresas y Personas (LREP), publicada en el diario oficial el 9 de enero de 2014 y cuya entrada en vigencia ocurrió el 9 de octubre de 2014, constituye la nueva regulación concursal chilena. Dentro de los procedimientos de reorganización y liquidación contenidos en la $L R E P$, el único que posee causales o presupuestos objetivos de procedencia corresponde a las variantes del procedimiento concursal de liquidación. Según el artículo 117 LREP, la causal más habitual es aquella señalada en su $\mathrm{N} \circ 1$, que refiere al deudor que "(..) cesa en el pago de una obligación que conste en título ejecutivo con el acreedor solicitante (...)". Tal causal supone que la apertura de un procedimiento concursal de liquidación dependerá del incumplimiento del deudor respecto de un título ejecutivo. Es por ello que $A_{1}$ posee una alternativa procedimental tendiente a demandar a $\mathrm{D}$ en el $\mathrm{T}_{2}$, tanto por un procedimiento de tutela individual como por un procedimiento de tutela colectiva. Lo que se quiere señalar es que no se exige la existencia de una situación de insolvencia del deudor ni tampoco una crisis generalizada. Basta el cese en el pago de una obligación que conste en título ejecutivo con el solicitante. Por su parte, los procedimientos concursales de reorganización no poseen presupuestos objetivos de apertura, la exigencia de cese en el pago de las obligaciones del deudor, no es siquiera exigible para su inicio. El deudor y sus acreedores pueden proceder a reestructurar el pasivo y el activo del primero previendo una insolvencia futura (artículos 60 y 105 , ambos de la $L R E P$ ). De esta forma, puede existir apertura de un procedimiento de reorganización en el ejemplo expuesto, incluso antes de $T_{2}$, si es que el $D$ informa a $A_{1}$ y $A_{2}$, que no estará en condiciones de pagar sus acreencias, o bien, una vez en $T_{2}$, en la medida que se alcance un acuerdo con tales acreedores.

$\mathrm{Al}$ respecto podemos concluir que: $i$ ) Cada vez que un deudor incumple sus obligaciones el acreedor tendrá alternativas de tutela individual y colectiva para perseguir el pago de sus créditos; ii) En Chile tanto la tutela individual y colectiva están basadas en el incumplimiento del deudor de sus obligaciones o en el actuar preventivo a tal incumplimiento, sin que se exija insolvencia; iii) Incluso si tal situación de insolvencia existiera es posible que nunca hayan procedimientos concursales, si los acreedores decidan libremente ejercer sus derechos por medio de la tutela individual; iv) Por otro lado, si tal situación de insolvencia no concurre es posible que 
se produzca la apertura de un procedimiento concursal, si el deudor desea reestructurar preventivamente su pasivo y activo, o bien, si un acreedor posee un título ejecutivo, vencido y no pagado.

Tales conclusiones demuestran que ninguna situación de déficits patrimonial conduce unívocamente a una vía procedimental determinada. Ello permite sostener que en Chile en materia de acción colectiva de los acreedores es un terreno fértil para el fenómeno del forum shopping procedimental.

\section{LOS INCENTIVOS DE LOS DEUDORES Y ACREEDORES EN PRESENCIA DEL FENÓMENO DEL FORUM SHOPPING PROCEDIMENTAL}

Cuando nos referimos a los incentivos a favor del forum shopping procedimental estamos haciendo mención a los estímulos normativos que afectan las decisiones de deudores y acreedores para optar por algunas de las vías procedimentales descritas. En concreto referimos estímulos para la acción, esto es, la manera en que ciertos instrumentos y herramientas adjetivas inducen a alguno de los sujetos mencionados a elegir un procedimiento en particular. A efectos de tratar de manera uniforme esta sección, cuando nos refiramos al fenómeno del forum shopping, lo haremos con una connotación negativa, dando cuenta de situaciones provocadas por ciertos sujetos que buscan obtener una ventaja por la elección de la vía adjetiva. No se trata simplemente de elecciones que persiguen el procedimiento más adecuado para los intereses del sujeto en cuestión, en escenarios en donde existe armonía entre el interés privado y social.

Se tratará de indagar, por tanto, en aquellas hendiduras, vacíos e imperfecciones de la normativa, que habilitan a los sujetos a extraer un beneficio en la selección de una tramitación determinada que lo coloque en una situación de privilegio frente a sus contrapartes. Se indagará en ejemplos que concretizan incentivos normativos en la materia. Veremos que los incentivos de deudores y acreedores están entregados por la legislación de manera interrelacionada a cada uno de esos sujetos. Tal escenario permite configurar supuestos de dominancia de alternativas (dominancias estrictas y débiles), que significan que la legislación entrega a tales sujetos (deudores/acreedores) la opción de elegir una opción que dominará (estricta o débilmente) a su alternativa, dependiendo de cómo y cuándo elijan jugar sus oponentes. En este sentido, en la sub-sección III.1 supondremos que quién elije primero es el deudor, y en la sub-sección III.2 supondremos que quién elige primero es el acreedor. De esta forma, denominaremos con la letra $\mathrm{A}$ al deudor en la sub-sección III.1, y con la letra $\mathrm{A}^{*}$ al acreedor en la 
sub-sección III.2. A su vez, el acreedor será denominado con la letra B en la sub-sección III.1, y con la letra $\mathrm{B}^{*}$ se denominará al deudor en la subsección III.2. En esas sub-secciones se examinarán ejemplos normativos de forum shopping, viendo de qué manera se configuran las dominancias estrictas y débiles para $A, A^{*}, B$ y $B^{*}$.

\section{Incentivos de los deudores en presencia del fenómeno del forum shopping procedimental}

En presencia de la acción colectiva de los acreedores, aquellos sujetos que pueden alcanzar mayores beneficios al optar por un procedimiento corresponden a los deudores. Por tanto, si los costos de entrada al procedimiento concursal son reducidos y los beneficios permiten satisfacer fines estratégicos -incluso de corto plazo-, entonces, pueden generarse una elección de procedimiento que solo persiga satisfacer tales consideraciones estratégicas. Se centrará el examen en la posibilidad normativa contenida en la $L R E P$ de que una vez iniciado el procedimiento concursal, el deudor opte por vías de reorganización en más de una oportunidad, maximizando la espera de una viabilidad futura. Tal decisión estratégica afecta la eficiencia concursal ex post al demorar más de lo razonable la vía procedimental que conducirá a dar satisfacción a los acreedores, aumentando los costos del error concursal e introduciendo presión en costos concursales directos e indirectos.

En efecto, el artículo 88 de la $L R E P$ regula lo que he denominado la segunda chance de la reorganización ${ }^{31}$. En este sentido, en la legislación mencionada, salvo excepciones, se otorga la posibilidad de volver a plantear una reorganización, a pesar que haya fracasado una con anterioridad. En este sentido, la única norma de clausura a una nueva propuesta de reorganización se contiene en el artículo $88 L R E P$, cuando a propósito de la impugnación del acuerdo de reorganización aprobado, señala que la resolución que acoge tal impugnación en base a las causales del $\mathrm{N}$ o 4 y 5 del artículo 85, impedirá que posteriormente pueda volver a plantearse un nuevo acuerdo de reorganización. Sin embargo, no existe impedimento para que se plantee una nueva reorganización, de concurrir las otras causales de impugnación de los $\mathrm{N}^{\circ} 1,2,3$ y 6 del artículo 85 LREP, ni tampoco existe impedimento de doble chance de reorganización en los casos en que un procedimiento anterior haya dejado de producir efectos por nulidad (artículo 97 LREP), o por incumplimiento (artículo 98 LREP).

${ }^{31}$ Carrasco, Nicolás y NúNEzez, Raúl, Conceptos generales del Análisis Económico del Derecho Concursal, en Carrasco, Nicolás y NúNEZ, Raúl (coordinadores), Presente y Futuro del Derecho Procesal Concursal Chileno. Una revisión desde el Análisis Económico del Derecho (Santiago, Editorial LegalPublishing, 2014), p. 61. 
Interesante es considerar la segunda chance de reorganización en caso de concurrir incumplimiento a uno anterior. La lógica detrás de esta segunda chance, es que a pesar que el deudor no satisfizo alguna de las exigencias de la reorganización anterior, podrá eventualmente volver a plantearse un nuevo acuerdo ¿Dónde se encuentra el problema?, la dificultad surge del hecho que la opción inicial por una reorganización supuso una elección entre tal alternativa y un procedimiento concursal de liquidación. En este sentido, en el marco de la decisión relativa a iniciar una reorganización se debe considerar, por una parte, la viabilidad del acuerdo al establecer el artículo $58 \mathrm{~N}$ o 8 letra a) $L R E P$, que el veedor deberá emitir un informe que incluya entre otros aspectos "Si la propuesta es susceptible de ser cumplida, habida consideración de las condiciones del deudor"; como también, la alternativa de realización de activos propia de un procedimiento concursal de liquidación, al establecer la norma referida en su letra b, que el veedor también deberá informar acerca de "El monto probable de recuperación que le correspondería a cada acreedor en sus respectivas categorias, en caso de un Procedimiento Concursal de Liquidación".

Pues bien, si inicialmente se optó por el procedimiento concursal de reorganización, entonces se valoró de mejor forma el factor de viabilidad del acuerdo versus el factor de monto probable de liquidación de los activos del deudor. Esa decisión genera ganadores y perdedores, y muy probablemente dentro de los primeros tendremos al deudor y dentro de los segundos tendremos a algunos acreedores. Sin embargo, si la reorganización se incumple ${ }^{32}$, esa valoración inicial resultó prospectivamente errada, toda vez que, la reorganización no era susceptible de ser cumplida. Con todo, y dado que un incumplimiento basado en el artículo 88 LREP no impide que un acuerdo de reorganización vuelva a ser planteado, nuevamente tendremos la posibilidad de valorar entre el factor de viabilidad y el factor de monto probable de realización de activos.

Los problemas que surgen de tal escenario son varios. En primer lugar, la posibilidad de una segunda chance de reorganización, cuando ya se ha demostrado que no concurren condiciones de viabilidad del deudor resulta en una afectación de la eficiencia concursal ex post. Tal finalidad corresponde al objetivo concursal de mejorar las tasas de recuperación crediticia a favor de los acreedores ${ }^{33}$. Para alcanzarlo debe existir una decisión adecuada entre las vías procedimentales que la legislación contemple al

${ }^{32}$ Concurrencia del supuesto del artículo 98 LREP.

${ }^{33}$ HarT, Oliver, Different approaches to Bankruptcy, en National Bureu of Economic Research (2000), p. 3 [visible en internet: http://www.nber.org/papers/ w7921]. En el mismo sentido: Bullow, Jeremy y Shoven, John, The Bankruptcy Decision, en The Bell Journal of Economics 9 (1978) 2, pp. 437-456; WARrEN, Eliza- 
efecto (reorganización/liquidación) ${ }^{34}$, de forma que, una secuencia de malas elecciones procedimentales, se traducirá en un detrimento de tal objetivo.

En segundo lugar, la posibilidad de segunda chance de reorganización implica un costo concursal del error. El error concursal se conceptualiza como de tipo I cuando se opta indebidamente por una reorganización debiendo elegirse una liquidación y como error de tipo II, cuando ocurre lo contrario ${ }^{35}$. En este sentido, en la doble chance de reorganización existe un error de tipo I, que puede repetirse si es las condiciones de viabilidad del deudor no mejoran en la segunda chance. La literatura ha detectado que los errores concursales de tipo I se encuentran vinculados con mayores costos concursales de tipo directo (tiempo y desembolsos que supone el proceso concursal) ${ }^{36} \mathrm{y}$ con mayores costos concursales indirectos (pérdida de valor de los bienes afectos al concurso en razón de des-utilización, inactividad,

beth, Bankruptcy Policy in an Imperfect World, en Michigan Law Review 92 (1993) 2, pp. 354-356, y CarrasCo, Nicolás y NúÑEZ, Raúl, cit. (n. 31), pp. 12-30.

${ }^{34}$ Puede verse: JaCKSON, Thomas, Bankruptcy, Non-Bankruptcy Entitlements, and the Creditors' Bargain, en The Yale Law Journal 91 (1982) 5, p. 869-870, y Longhofer, Stanley y Peters, Stephen, Protection for whom? Creditor conflict and Bankruptcy, en American Law and Economic Review 6 (2004) 2, pp. 249-251.

35 Puede verse: Eger, Thomas, Bankruptcy Regulations and the New German Insolvency Law from an Economic Point of View, pp. 14-15 [visible en internet: http://www.researchgare.net/publication/5145554]; ZIPITRÍA, Leandro, Un análisis económico-institucional de los procedimientos concursales en el Uruguay (Facultad de Ciencias Económicas y de Administración, Universidad de la República Oriental de Uruguay, 2000), p. 36, y Blazy, Regis y CHOPARD, Bertrand, Ex-post Efficiency and Bankruptcy Procedure: A General Normative Approach, en International Review of Law and Economics 24 (2004) 4, pp. 447-471.

36 Véase: Bradley, Michael, The Untenable Case for Chapter 11, en Yale Law Journal 101 (1992) 5, pp. 1043-1095; Cutler, David y Summers, Lawrance, The Costs of Conflict Resolution and Financial Distress: Evidence from the Texaco-Pennzoil Litigation, en Rand Journal of Economis 19 (1987) 2, pp. 157-172; MoONEY, Charles, A Normative Theory of Bankruptcy Law: Bankruptcy As (Is) Civil Procedure, en Faculty Scholarship, Paper 18, p. 941 [visible en internet: http://scholarship.law.upenn.edu/ faculty_scholarship/18]; GonzÁlez, Víctor Manuel y GonzÁlez, Francisco, Procedimientos de resolución de insolvencia financiera en España: Costes de insolvencia y trasferencias de riqueza, en Investigaciones Económicas XXIV (2000) 2, p. 364; WARNER, Jerold, Bankruptcy Costs: Some Evidence, en The Journal of Finance XXXII (1997) 2, p. 338, donde incluye directamente como costo concursal directo el tiempo, y Brealey, Stewart y Myers, Franklin, Principles of Corporate Finance (2a edición, New York, McGraw-Hill, 1984), p. 395. 
etc) ${ }^{37}$. Así la posibilidad de incurrir dos veces en costos de error concursal de tipo I debe ser evitada ${ }^{38}$.

En tercer lugar, la doble chance de la reorganización produce incentivos inadecuados en materia de forum shopping, tanto para el deudor como para los acreedores valistas. En efecto, el deudor puede optar por una reorganización sin que exista una causal de insolvencia, o de cese en el cumplimiento de sus obligaciones (artículo 52 y 102 de la $L R E P$ ). Así, los costos de entrada a la reorganización son bajos, sin embargo, se reciben importantes beneficios derivados de la suspensión del ejercicio de los derechos de tutela individual de sus acreedores (artículos $2 \mathrm{~N}$ o 31, 57 $\mathrm{N}$ o 1 y 108 letra a. $L R E P)$. Asimismo, el deudor podrá continuar en la administración (artículo $57 \mathrm{~N}$ o 2 LREP), lo que de acuerdo a la literatura especializada significa una mayor posibilidad de riesgo de extracción de recursos en desmedro de sus acreedores ${ }^{39}$. De esta forma, la opción de la reorganización abre la alternativa para el deudor de un respiro momentáneo frente a la persecución de sus acreedores, prefiriendo tal alternativa frente a la existencia de múltiples ejecuciones individuales. Si el deudor opta por la reorganización tendrá un aliado: el acreedor valista. La razón de esa alianza se debe a que ambos sujetos poseen una misma visualización de incentivos futuros. Tal incentivo se concretiza en la posibilidad que la suerte del deudor cambie. Tal escenario (aunque, incierto) es preferido a la alternativa de la liquidación. En efecto, el deudor prefiere jugarse todas las opciones por una reorganización, ya que así tendrá alguna posibilidad de subsistir; en el caso de los acreedores valistas, si el deudor llega a mejorar su suerte en una reorganización, tendrán alguna esperanza de recuperar algún crédito, lo que no existe de seguirse una liquidación ${ }^{40}$. Por lo mismo, la segunda

37 Véase: Chen, GM y Merville, Larry, An analysis of the underreported magnitude of the total costs of financial distress, en Review of Quantitative Finance and Accounting 13 (1999) 3, pp. 277-293, y Altman, Edward, A Further Empirical Investigation of the Bankruptcy Cost Question, en The Journal of Finance XXXIX (1984) 4, pp. 1070-1071.

38 En este sentido, según White, Michelle, Bankruptcy Costs and the New Bankruptcy Code, en Journal of Finance, 38 (1983) 2, pp. 477-487, los costos concursales directos e indirectos de una indebida tramitación inicial de reorganización significó gastos para el sistema judicial concursal norteamericano ascendientes a la cantidad de 9 billones de dólares el año 1980.

${ }_{39}$ Puede verse: Вевсниск, Lucian, Ex ante costs of violating absolute priority in bankruptcy, en Discussion Paper Harvard Law School 328 (2011), pp. 6, y RHODESKropf y Viswanathan, S., Corporate reorganizations and non-cash auctions, en Journal of Finance 55 (2000) 4, pp. 1807-1849.

${ }^{40}$ Así BAIRD, Douglas y JACKSON, Thomas, cit. (n.1), p.107: "By contrast, junior parties, who, under current law, are typically general creditors and shareholders, 
chance de reorganización, establece incentivos para la elección del forum shopping a favor del concurso, por parte del deudor, y una vez, dentro del proceso concursal, tal incentivo se traduce en maximizar las posibilidades de la reorganización. En tal finalidad, contará con la ayuda de los acreedores valistas, no siendo escasas las posibilidades de esa segunda chance.

Dada tal estructura, entonces el deudor A escogerá el concurso como opción estrictamente dominante frente a las elecciones que los distintos acreedores $\mathrm{B}$ puedan haber adoptado previamente. De hecho, la elección del procedimiento concursal por A opera con independencia a la elección previa de $\mathrm{B}$ de alguna vía procedimental determinada, toda vez que, si los acreedores $\mathrm{B}$ eligieron la alternativa de los procedimientos de tutela individual, a causa de la elección concursal de $\mathrm{A}$, tales procedimientos individuales se suspenderán; por otro lado, si los acreedores B optaron por la vía concursal, A podrá dar inicio a una reorganización, incluida su segunda chance. De esta forma, cualquiera sea la elección que adopten los acreedores $\mathrm{B}$, la alternativa de $\mathrm{A}$ por una reorganización será dominante. Para la efectividad de tal alternativa, se requiere del apoyo de los valistas, lo que será obtenido si concurren incentivos idénticos con el deudor, en cuanto a maximizar la espera de una eventual viabilidad futura.

Si bien el ejemplo de la doble chance de la reorganización demuestra una inadecuada regulación normativa, existen ciertas reglas contenidas en la $L R E P$ que cierran la posibilidad al deudor de provocar el fenómeno del forum shopping procedimental en materia de acción colectiva de los acreedores. Me refiero a la clausura de procedimientos concursales por la existencia de vías ejecutivas previas. Así ocurre con el procedimiento concursal de renegociación de la persona deudora, ya que de conformi-

often have interests that pull them in the opposite direction. Members of any group of investors that would be eliminated by a present liquidation or sale of assets have nothing to lose by seeking a solution that avoids a final distribution today. A group that would get nothing if the business ceases will resista $\mathrm{n}$ immediate liquidation, even if liquidation is best for owners as a group. If there is any chance, however remote, of an upswing that will bring them value, they will want to take that chance [...]" (Trad. del autor: "Por el contrario, los valistas, quienes bajo la ley actual, son normalmente los acreedores generales y los accionistas, a menudo tienen intereses que los arrastran a la dirección contraria (a los acreedores privilegiados). Los miembros de cualquier grupo de inversionistas que fueran eliminados por una presente liquidación o venta de bienes, no tienen nada que perder al buscar una solución que evita una distribución final al día de hoy. Un grupo que no obtenga nada si la empresa suspende sus actividades pondrá resistencia a una liquidación inmediata, inclusive si la liquidación es la mejor solución para los dueños como grupo. Sin embargo, si hay alguna oportunidad, aunque sea remota, de una reactivación que les de valor, ellos querrán tomar esa chance (...)”. 
dad al artículo 260 inciso $2^{\circ}$ LREP no se dará inicio a tal procedimiento si la persona deudora ha sido notificada de un procedimiento concursal de Liquidación o de cualquier otro juicio ejecutivo. De esta forma, el legislador destruye la opción estrictamente dominante del deudor A, no siendo irrelevante la opción previa de los acreedores B. En efecto, si estos últimos actúan iniciando un procedimiento de tutela individual o colectiva con anterioridad al deudor, entonces, este último tendrá vedada la renegociación. Entonces, en este caso, se trata de una opción moderadamente dominante para A, solo en caso que actúe primero que sus acreedores B. En este caso existe un mayor control de los escenarios posibles por los acreedores, ya que si desean evitar las consecuencias indeseadas de la renegociación, entonces, demandarán tempranamente. Tal alternativa no solamente es consistente con la protección del interés particular de los acreedores $\mathrm{B}$, sino que además, es plenamente acorde con el interés social de detectar a tiempo situaciones de insolvencia o de incumplimientos que releven una situación de incapacidad para hacer frente al pago de las obligaciones por parte de los deudores A. En efecto, se ha estimado que la oportuna denuncia de los incumplimientos del deudor mejora los índices de eficiencia concursal ex ante ${ }^{41}$.

2. Incentivos de los acreedores en presencia del fenómeno del forum shopping procedimental

Los acreedores también posee incentivos relevantes en materia de elección colectiva en que se traduce el asunto concursal. En esta sub-sección examinaremos los siguientes cuatro ejemplos de incentivos a los acreedores en materia de forum shopping: a) incentivos para iniciar un procedimiento concursal en presencia de causales de apertura de mínima; b) incentivos para solicitar el inicio del procedimiento concursal cuando los acreedores sean compañías de seguro; c) incentivos para solicitar el inicio de acciones ejecutivas individuales con énfasis en los acreedores bancarios y financieros, yd) incentivos de los acreedores con garantía dentro de los procedimientos concursales.

a) Incentivos para el inicio de un procedimiento concursal en presencia de causales de apertura de minima. Hemos mencionado que la regulación concursal tiene un contenido procesal. De esta forma, las aplicaciones del análisis económico del derecho procesal servirán para poder dilucidar cuando un sujeto optará por un procedimiento colectivo de esa naturaleza.

${ }^{41}$ Bisogno, Marco y De LuCA, Roberto, Bankruptcy Effiency and Indirect Cost in Italian SMEs: a Temporal Approach, en International Journal of Business Research and Development 3 (2014) 2, p. 19. 
Así, existirán procedimientos concursales cuando los beneficios que se deriven de su inicio -el valor del derecho multiplicado por la probabilidad de una sentencia favorable- sean superiores a los costos que el procedimiento supone. Una de las formas de desincentivar los procedimientos concursales es por medio del aumento de los costos directos del concurso, por lo mismo, la cuantía de esos costos resulta una variable a ser considerada. Pues bien, según Cabrillo ${ }^{42}$, la persona que pretenda dar inicio a un procedimiento concursal lo hará sólo si la cuantía esperada de un resultado favorable matizada por la tasa de descuento en razón del tiempo esperado del proceso es superior a los gastos del juicio.

Rasmussen ha señalado que existen incentivos negativos para que en ciertos casos los acreedores valistas puedan recurrir a los procedimientos concursales. En este sentido, y siguiendo implícitamente lo sostenido por Marinc y Vlahu ${ }^{43}$, ciertos acreedores valistas pueden verse afectados con la declaración del concurso en razón de la aplicación de la regla de pro-rata de pago que rige a los valistas. Ahora bien, Rasmussen señala que no solamente el concurso perjudicaría las posibilidad de pago de tales acreedores frente a lo que sucede con los acreedores privilegiados, sino que también, la regla mencionada puede incrementar las posibilidades de compartir pérdidas con los valistas, transformando la cuantía esperada de un resultado favorable del concurso en prácticamente nula ${ }^{44}$. Si bien, Rasmussen no señala un ejemplo concreto, creo que podría adecuarse a tal situación la de un acreedor valista que haya monitoreado la situación de crisis del deudor y haya iniciado un procedimiento ejecutivo embargando algunos bienes de éste (que no garanticen obligaciones de acreedores privilegiados), siempre que se encuentre en etapas cercanas a la venta de tales activos. En este ejemplo, la expectativa de pago en la ejecución individual será mayor que aquella que puede esperar del concurso. Tal escenario normal de incentivos para el inicio de un procedimiento concursal se ve alterado en ciertos

42 Cabrillo, Francisco, Quiebra y liquidación de empresas (1a edición, Madrid, Unión Editorial, 1989), p. 41.

${ }^{43}$ Marinc, Matej y Vlahu, Razvan, The Economics of Bank Bankruptcy Law (Heidelberg, Springer, 2012), p. 7.

${ }^{44}$ RaSmussen, Robert, Ex Ante Effects of Bankruptcy Reform, en Washington University Law Quarterly 72 (1994) 3, p. 1190, señala: “The firm's creditors have little incentive to initiate a bankruptcy proceeding. Once creditors discover that the firm is in financial distress, they have an incentive to seek payment in full. Bankruptcy law imposes a pro rata sharing rule" (Trad. del autor: "Los acreedores del deudor tienen pocos incentivos para iniciar un procedimiento de quiebras. Una vez que los acreedores descubren que la empresa deudora se encuentra en problemas financieros, ellos tienen un incentivo para buscar el pago en su totalidad. La ley de quiebras impone una regla de distribución pro-rata (que perjudicaría tal finalidad"). 
supuestos. En efecto, en presencia de determinados acreedores -compañías de seguro- existirá mayor cantidad de procedimientos concursales que el normal (apartado b); por el contrario, dada la existencia de otros acreedores -fundamentalmente, bancarios- existirán menos procedimientos concursales que lo habitual (apartado c).

Ahora bien, la legislación concursal chilena establece un requisito de mínima para que los acreedores den inicio a un procedimiento concursal. Como hemos indicado, la causal principal corresponde al "cese en el pago de una obligación que conste en título ejecutivo con el acreedor solicitante" (artículo $117 \mathrm{~N}$ o 1 LREP). Tal exigencia de mínima no requiere demostrar una insolvencia actual o inminente como ocurre con el artículo 2 de la Ley 22/2003, de 9 de julio, Ley Concursal Española, o con la InsolvenzOrdnung alemana, $\$ 18$ Ins $O$.

Para algunos autores tal exigencia de mínima supone un incentivo para que los acreedores utilicen el concursal para presionar el pago de sus créditos $^{45}$. En este sentido, si el deudor no estuviera en situaciones de insolvencia real, la posibilidad de iniciar un procedimiento concursal pudiera verse favorecido por la existencia del derecho que posee el deudor para liberarse del concurso consignando la cantidad reclamada más las costas (artículo $120 \mathrm{~N}$ o 2 letra a) LREP). Por tanto, si un deudor con problemas de liquidez no desea verse involucrado en un procedimiento concursal hará todo lo posible por conseguir el dinero para impedir el concurso en la audiencia inicial (artículo 120 LREP). Así, la consignación del deudor constituye una vía de cobro rápida favorecida por la legislación, que opera sobre la amenaza del concurso. Los críticos a esta posibilidad cuestionan que la alternativa concursal dejaría de ser de última ratio.

Más allá esas críticas, es importante constatar que la posibilidad que el acreedor peticionario obtenga el pago de su crédito vía consignación en la audiencia preliminar, constituye uno de los incentivos normativos que la $L R E P$ establece para favorecer el forum shopping procedimental a favor del concurso. En este caso, si el acreedor sabe que el deudor posee problemas de liquidez y varios acreedores, pero también sabe que tiene la posibilidad de acceder a financiamiento para consignar su crédito, y tal financiamiento resulta más barato que el costo que supone el concurso, entonces, la alternativa concursal será estrictamente predominante para los acreedores $\mathrm{A}^{*}$ que se encuentren en tal escenario, frente a cualquier otra alternativa de tutela ejecutiva individual.

${ }^{45}$ Bofill, Octavio y ARAYA, Ignacio, Análisis y comentarios a la reforma al régimen concursal chileno. en Revista de Derecho Escuela de Postgrado - Universidad de Chile 4 (2013), pp. 287-288. 
b) Incentivos para solicitar el inicio del procedimiento concursal en presencia de acreedores que sean compañias de seguro. Un caso particular en el análisis de los incentivos se plantea respecto de las compañías de seguro, quienes tienen mayores incentivos para dar inicio a procedimientos concursales sin atender suficientemente a la viabilidad de las empresas. Así, Cabrillo señala que las compañías de seguro son un optimizador del máximo beneficio a largo plazo, en una serie de procedimientos concursales. Así, la conducta ejercida en un concurso producirá expectativas en casos futuros, sabiendo los deudores cuál será la conducta de la compañía de seguros en concursos futuros ${ }^{46}$. En consecuencia, las compañías de seguro tienen incentivos para instar una mayor cantidad de procedimientos concursales frente a la existencia de causales de apertura del concurso. Ello puede resultar en un perjuicio en el sistema al producir mayor cantidad de errores concursales tipo II (liquidar empresas viables), ya que ellos no poseen interés en la reorganización. En efecto, los beneficios concursales de las compañías de seguro están asociados al efecto que su actuación producirá en el largo plazo en el resto de los deudores. Tal efecto negativo no se ve compensado con eventuales externalidades positivas que pudieran derivarse de su actuación, vinculadas con la generación de bienes públicos como el precedente (generado por la actuación de la administración de justicia y que produce certeza en los destinatarios de las normas ${ }^{47}$ ); en este sentido, no hay externalidad positiva en la actuación de esos acreedores en relación al conocimiento de cuál será su actuar como litigante (pedir mayor cantidad de concursos que el habitual), ya que ese comportamiento solamente satisface el interés privado de las aseguradoras y no el interés público de que se adopte la decisión procedimental que corresponda a la viabilidad del deudor.

Las compañías de seguro no pensarán solo en el caso en particular, sino en el efecto sistémico que su comportamiento pueda generar para situaciones futuras. Muy probablemente estos acreedores $\mathrm{A}^{*}$ impedirán el acceso a un procedimiento de renegociación en el supuesto del artículo 260 inciso 2 LREP ya analizado, y además, si desean perseguir la liquidación, no concurrirán con el resto de los valistas favoreciendo la reorganización en una primera o segunda chance. En suma, a mayor proporción de pasivo sostenido por compañías de seguro, menor probabilidad de vías de reorganización para el deudor $\mathrm{B}^{*}$.

c) Incentivos de los acreedores para solicitar el inicio de acciones ejecutivas

${ }^{46}$ Cabrillo, Francisco, cit. (n. 42), pp. 107-108.

47 Correa, Jorge; Peña, Carlos; VArgas, Juan Enrique, ¿Es la justicia un bien público?, en Revista Perspectivas, Departamento de Ingeniería Industrial - Universidad de Chile 3 (2000) 2, pp.403-406. 
individuales frente a la alternativa concursal. A diferencia de lo que sucede con las compañías de seguro, los acreedores bancarios y financieros solicitan el inicio de procedimientos concursales en una menor cantidad de casos de lo habitual. Ellos prefieren el inicio de acciones individuales de cobro. En este sentido, los bancos habitualmente son acreedores privilegiados con garantías. Para tales sujetos la recuperación de sus acreencias resulta más segura que para los valistas ya que existen medidas de aseguramiento -generalmente, contractuales y de garantía reales- que buscan evitar que el cese en el pago de sus créditos les genere situaciones de riesgo de no reintegro. Así, tales acreedores tienen a su disposición la posibilidad de perseguir las garantías para el evento que exista incumplimiento a las obligaciones principales. Tal persecución ocurrirá individualmente en la generalidad de los supuestos -salvo tercerías de prelación-, de forma que la vía ejecutiva individual no involucrará gastos adicionales a los que esa alternativa implica. Sobre esta materia existe evidencia empírica en el derecho comparado ${ }^{48}$. Por otro lado, y considerando que la garantía resguarda cierto monto de crédito, el procedimiento asociado a su ejecución no modificará la expectativa de cobro, sino que el porcentaje de recuperación. Así, un litigante racional siempre privilegiará aquel procedimiento que exija el menor desembolso de gastos.

Es entendible, entonces, las razones por las cuales los acreedores financieros, que normalmente garantizan los préstamos que otorgan, no sean un solicitante frecuente de procedimientos concursales. En este sentido, de la revisión de la base de datos elaborado por la antigua Superintendencia de Quiebras, tenemos que de los 4868 procedimientos concursales vigentes en Chile en el año 2013, ninguno de ellos se inició por solicitud de una institución bancaria o financiera ${ }^{49}$. Ocurre, entonces, que desde la

${ }^{48}$ En este sentido García, Miguel y Mora, Juan, El uso de los concursos de acreedores en España, en Boletín Económico. Banco de España (2012), p. 33: "En consecuencia, dado que la ejecución hipotecaria es aparentemente un procedimiento relativamente más rápido, menos costoso y que no diluye los derechos de cobro de los acreedores -lo que potencialmente debería conllevar tasas de recuperación del crédito más altas-, las ejecuciones hipotecarias se perfilarían, según este razonamiento, como una alternativa más atractiva que el concurso de acreedores como forma de hacer frente a la insolvencia empresarial en España”. En cuanto a la duración del concurso en España la misma tiene una tasa promedio el año 2007 de 20,23 meses versus los 7,9 meses de la ejecución individual. En el mismo sentido, según FrisBY, Sandra, Report on Insolveny Outcomes, en The Insolvency Service Report, (2006), p. 1-9, la tasa de duración de los procedimientos concursales en Inglaterra alcanzaría menos de 12 meses versus los 8,12 meses de las ejecuciones individuales, para datos del año 2006.

${ }^{49} \mathrm{Al}$ respecto se puede consultar en: [visible en internet: htpp://190.196.10.41/ AtencionPublicoWeb/registroQuiebra.do]. 
perspectiva de la maximización del bienestar general, tales acreedores no tienen incentivos para hacer coincidir sus intereses con aquello socialmente óptimo, en cuanto a que el inicio del concurso ocurra cuando se generan situaciones de insolvencia. Tal efecto negativo se intensifica si consideramos que normalmente serán esos mismos acreedores, en razón de sus garantía, los que se encuentran en mejores condiciones de fiscalizar la insolvencia del deudor. Se produce, por tanto, la necesidad de un gasto de monitoreo superior al óptimo por parte del resto de los otros acreedores, los que no se encuentran en las mejores condiciones para hacerlo. Con todo, si bien los acreedores con garantía no poseen mayores incentivos para solicitar el inicio de un procedimiento concursal, de todas formas pueden verse en la necesidad de concurrir a un procedimiento concursal en razón de la petición de otro acreedor o de un deudor. Ello se examinará en el apartado d).

Adicionalmente, el grupo de acreedores que se dedican por razón de su giro a operaciones de crédito de dinero, o bien, que habitualmente adquieren carácter de acreedor en razón de obligaciones civiles y comerciales, se encuentran en condiciones de poder castigar créditos incobrables, por medio de la correspondiente deducción como gasto de tales créditos. Se trata de un beneficio tributario que tiene incidencia en la elección del forum shopping procedimental que estamos estudiando. Al respecto debemos referirnos al artículo 31 inciso $3 \mathrm{~N}$ o4 de la Ley de Renta. Los requisitos para que tal norma opere, son: $i$ ) que los créditos provengan de operaciones relacionadas con el giro del negocio; ii) que el castigo de tales créditos incobrables haya sido contabilizado oportunamente, y iii) que respecto de ellos se hayan agotado prudencialmente los medios de cobro ${ }^{50}$.

El requisito que nos interesa es el tercero. En efecto, de cuál sea el nivel de exigencia para entender "agotado prudencialmente los medios de cobro", dependerá el procedimiento cobro de créditos que sea exigible. En este sentido, planteado un asunto de acción colectiva de acreedores, éstos poseen distintos mecanismos por los cuales buscar el pago de sus créditos. $\mathrm{Al}$ respecto, la manera en que se ha entendido tal requisito supone un favorecimiento por la vía de tutela individual de cobro. De esta forma, un acreedor que pretende hacer valer el beneficio del artículo 31 inciso $3 \mathrm{~N}$ - 4 Ley de Renta, no necesita dar inicio a un procedimiento concursal. En este sentido, se pronuncia la Circular N o 24 de Servicios de Impuestos Internos. Tal Circular en "consideración a las prácticas usuales de mercado" entiende que se han agotado prudencialmente los medios de cobro para

50 Servicios de Impuestos Internos, Circular No 24, del 24 de abril de 2008, "Tratamiento tributario de castigo de créditos incobrables, conforme lo dispuesto por el $\mathrm{N}$ o 4, del artículo 31 de la Ley de Renta”. 
efectos del castigo: i) si se han ejercido "acciones o medios razonables de acuerdo a la cuantía de la deuda" en caso de créditos incobrables cuyo monto por cliente al término del ejercicio no superen 10 Unidades de Fomento; ii) si se han "ejecutado procedimientos de cobranza extrajudicial", en caso de créditos incobrables cuyo monto al término del ejercicio, por cliente exceda de 10 Unidades de Fomento y no superen las 50 Unidades de Fomento, y iii) si se ha "requerido judicialmente al deudor" en el caso de créditos incobrables cuyo monto al término del ejercicio, por cliente sea superior a 50 Unidades de Fomento. En los tres casos, no se exige el inicio de un procedimiento concursal.

Entonces, un acreedor racional enfrentado a un problema de acción colectiva, en donde tiene a su disposición dos mecanismos de cobro (tutela judicial individual y colectiva), elegirá la más económica. La más económica será siempre la acción de tutela judicial individual, ya que, los honorarios de abogados son menores que aquellos que es necesario para iniciar un procedimiento concursal (en razón de la especialidad), y además, no requiere el pago de la consignación previa de 100 Unidades de Fomento que es exigido para incoar un procedimiento concursal de liquidación (artículo $118 \mathrm{~N}$ o 2 LREP).

De esta forma, para los acreedores $A^{*}$ que se han analizado en esta sección, la alternativa ejecutiva individual predomina sobre la opción concursal. Sin embargo, tal elección se encuentra dominada por la opción del deudor $\mathrm{B}^{*}$ de dar inicio a un procedimiento concursal, toda vez que, aun cuando el deudor $\mathrm{B}^{*}$ actúe después que los acreedores $\mathrm{A}^{*}$, de todas formas, llevará el foro de la discusión al concurso, dada las reglas de acumulación de juicios que se contemplan en la $L R E P$ (artículos $129 \mathrm{~N}$ o 5 , $142,143,144,145,146$ y 147 LREP). En efecto, el artículo 144 LREP establece que en los procedimientos ejecutivos por obligación de dar, se deberá remitir al juez que conoce del concurso para seguir tramitándose en tal proceso. Lo anterior, obligará a los acreedores $\mathrm{A}^{*}$ a verificar sus créditos y actuar en el concurso.

d) Los incentivos de los acreedores con garantía en el concurso. Los incentivos que los acreedores preferentes poseen dentro del concurso dependen de la manera en que la legislación concursal determine la protección de sus derechos. En lo sucesivo nos concentraremos en la regulación de la LREP respecto de los acreedores hipotecarios y prendarios. Una consideración previa. Según Baird y Jackson la naturaleza especial de los acreedores privilegiados (dentro de los que se encuentran los acreedores con garantía real), no es capturado por la relación deudor-acreedor, ya que todos los titulares de créditos poseen una relación de tal naturaleza. Su esencia emana de la especial negociación que permitió a tales acreedores alcanzar 
su posición de prioridad y los beneficios asociadas a ella. Nos referimos a condiciones de crédito más favorables ya que con la garantía se reduce la incertidumbre y el riesgo de no pago. Por su parte, el acreedor mejora sus probabilidades de satisfacción crediticia, al poder pagarse con la realización de los bienes en garantía ${ }^{51}$.

Con todo, la legislación concursal establece una serie de reglas que de alguna manera afectan la esencia del crédito privilegiado con garantía real. Tales reglas pueden maximizar el interés de tal acreedor en beneficio de la opción ejecutiva individual. En este sentido, si las normas concursales se traducen en un detrimento de sus probabilidades de pago en comparación con aquellas que poseen en la alternativa de ejecución individual, entonces, existirá un desincentivo para los acreedores privilegiados con garantía real de acudir al concurso. Sin embargo, tal efecto desde la óptica de los otros acreedores y del deudor, puede ser un incentivo por la alternativa concursal. De ser así, se genera el efecto del forum shopping procedimental en materia de acción colectiva de los acreedores.

Ahora bien, como primer asunto debemos diferenciar las reglas concursales aplicables al procedimiento de liquidación y al de reorganización. Se verá que las normas establecidas para el primer procedimiento concursal son menos disruptivas que las segundas respecto de los acreedores privilegiados con garantías reales. De esta forma, será racional en la mayoría de los casos que tales acreedores opten por tal mecanismo. En efecto, las reglas asociadas al procedimiento concursal de liquidación determinan que en general los derechos de los acreedores privilegiados con garantía real se protegen de manera similar a como ocurre en una situación no concursal. En este sentido, el artículo 135 LREP consagra que la resolución de Liquidación suspenderá los derechos de los acreedores hipotecarios y prendarios para ejecutar individualmente al deudor. Tal suspensión, si bien va en desmedro de las posibilidades de actuación de los mencionados acreedores en situaciones de no concurso, resulta indispensable para poder organizar la acción colectiva de los acreedores. La idea es afectar los derechos de esos acreedores solo en la medida necesaria.

Tal suspensión puede permanecer en el tiempo si se declare la continuidad definitiva de la actividad económica del deudor (artículo 233 LREP) ${ }^{52}$. Sin embargo, para que la suspensión afecte los derechos de ejecución de los acreedores hipotecarios y prendarios, durante el plazo de la continuidad (de hasta 1 año, prorrogable por una sola vez, de acuerdo al artículo 233

51 Douglas y Jackson, Thomas, cit. (n.1), p. 112.

52 Otro supuesto de suspensión existe enajenación del conjunto de bienes del deudor como unidad económica (artículo 219 LREP). 
$\mathrm{N}$ o 5 LREP), se requiere que esos acreedores hayan votado a favor de la misma. Su consentimiento es necesario para que tal suspensión los afecte. Tal consentimiento puede darse para evitar el fenómeno de fire-sale $e^{53}$ o venta en condiciones no apropiadas. Una de las maneras de evitar la venta a bajo precio en ciertas situaciones es precisamente mejorar las condiciones de la empresa concursada valorizando sus activos ${ }^{54}$.

Uno de los ejemplos que la $L R E P$ no desea alterar los derechos de los acreedores hipotecarios y prendarios, en el marco de un procedimiento concursal de liquidación, corresponde al derecho de éstos para continuar sus acciones o iniciarlas por las vías normales de ejecución (siempre que se alce la suspensión examinada), sin perjuicio de poder someter tales acciones a las normas de realización del procedimiento concursal de liquidación (artículo 135 inciso 2 LREP). Esta regla no disruptiva de los derechos de tales acreedores, se manifiesta en que las normas del pago se sujetan al derecho común, según se establece en el artículo 242 LREP respecto de los acreedores prendarios, y en el artículo 243 LREP, en relación a los acreedores hipotecarios, norma que remite a los artículos 2477, 2478, 2479 y 2480 del Código Civil. Sin embargo, se establecen límites a esa regla no disruptiva. Las restricciones vienen impuestas por el contexto de acción colectiva de los acreedores.

El primero de tales límites, se refiere a que los acreedores hipotecarios o prendarios, ya sea que decidan ejecutar sus derechos por las vías normales, o bien, por las reglas de realización del procedimiento concursal de liquidación, para poder percibir cualquier monto deben previamente "(...) garantizar el pago de los acreedores de primera clase" (artículo 135 $L R E P)$. Ello es una manifestación de las pautas de pago de los acreedores hipotecarios y prendarios en el marco de la Protección Financiera Concursal (artículo 75 LREP). El segundo de los límites se encuentra contenido en el artículo 239 inciso 2 y $3 L R E P$, según la cual, los créditos que se obtengan en la continuidad de las actuaciones económicas del deudor, prefieren en el pago a los acreedores hipotecarios y prendarios, solamente si los bienes no gravados comprendidos en tal continuidad, fueran insuficientes para

53 Puede verse: SHLEIFER, Andrei y Vishny, Robert, Liquidation values and debt capacity: A market equilibrium approach, en Journal of Finance 47 (1992) 4, pp. 13431366; Pulvino, Todd, Do asset fire-sale exist? An empirical investigation of comercial aircraft transactions, en Journal of Finance 53 (1998), pp. 939-978, y BERKOVITCH, Elazar y ISRAEL, Ronen, The bankruptcy decisión and debt contract renegotiation, en Review of Finance 2 (1998) 1, pp. 1-27.

${ }_{54}$ Smith, David y Strömbert, Per, Maximizing the Value of Distressed Assets: Bankruptcy the Efficient Reorganization of Firms, p. 13 [visible en internet: http:// www1.worldbank.org/finance/assets/images/Smith-Stromberg_Maximizing.pdf]. 
pagar los mencionados créditos. El tercer límite se encuentra regulado a propósito de la venta de bienes hipotecarios y prendarios que conforman una unidad económica. La ley establece que si en el conjunto de bienes a vender como unidad económica, existen bienes gravados con hipoteca o prenda, la Junta de Acreedores acordará su precio de venta. La valoración no podrá ser menor que el valor de avalúo fiscal o el valor que el liquidador les asigne (artículo 219 LREP). Así, es posible que los acreedores mencionados puedan verse desmejorados en sus probabilidades de pago, si la tasación del bien es menor al valor de su crédito. Tal riesgo puede ser aliviado en la medida que ellos inicien un incidente de rectificación de valor (artículo 219 incisos 2 a 4 LREP). La carga de prueba, con todo, recaerá en los acreedores reclamantes.

Del análisis de las normas indicadas tenemos que el procedimiento concursal de liquidación sigue en general la tendencia de no ser disruptivo respecto de los derechos que los acreedores hipotecarios y prendarios poseen en situaciones no concursales. Sus derechos procesales son conservados salvo excepciones, en relación a las cuales se contemplan algunos paliativos. En base a tales consideraciones es que existirán incentivos en esos acreedores para favorecer una liquidación, si se ven compelidos a participar en el concurso. Tal vía procedimental es la que se asemeja a las probabilidades de cobro que emanan de la especial relación de privilegio que poseen de acuerdo al derecho común. Tal conclusión se ve reforzada si es que examinamos las consecuencias que se siguen para los acreedores hipotecarios y prendarios de tramitarse un procedimiento concursal de reorganización. En tal procedimiento la regla no disruptiva de los derechos en situación no concursal se ve afectada.

En efecto, respecto del procedimiento concursal de reorganización judicial, la resolución que le da inicio (resolución de reorganización), va asociada a un efecto de suspensión y de prohibición de inicio de acciones de ejecución y cobro que afecta a todos los acreedores, incluidos los acreedores hipotecarios y prendarios (artículo $57 \mathrm{~N}$ o 1 LREP). Tal efecto no es distinto del que emana de la resolución de Liquidación (artículo 135 LREP). Su justificación se encuentra en la necesidad de coordinación que impone la acción colectiva de los acreedores. Sin embargo, las consecuencias disruptivas del procedimiento concursal de reorganización judicial vienen asociadas a los efectos de tal acuerdo una vez aprobado. En este sentido, el artículo $61 L R E P$ establece que la propuesta de reorganización puede comprender distintas clases, por ejemplo, propuestas para la clase de acreedores valistas y para la clase de acreedores hipotecarios y prendarios. Si éstos últimos desean votar la propuesta de los valistas, entonces pierden su preferencia y no podrán votar la propuesta diseñada para ellos. Por su parte, el artículo 
78 LREP establece que los acreedores hipotecarios y prendarios votarán de acuerdo al avalúo comercial de los bienes sobre los que recae la garantía, según conste en la nómina de créditos reconocidos. Pues bien, de acuerdo al artículo 79 LREP, un acuerdo de reorganización judicial será aprobado si cuenta con el voto de $2 / 3$ de los acreedores presentes en la audiencia citada al efecto, siempre que representen $2 / 3$ partes del total del pasivo de su clase. La aprobación de tal acuerdo pende de la condición suspensiva de que las otras clases también aprueben el acuerdo con los quórum señalados. Lo relevante es que si el acuerdo de reorganización judicial es aprobado, los bienes garantizados con hipoteca o prenda deberán seguir la suerte del acuerdo, en medida que sean declarados esenciales, y a pesar que el acreedor hipotecario o prendario respectivo, haya votado en contra de tal acuerdo (artículo $95 \mathrm{~N}$ o 1 LREP).

De esta forma, si el acreedor hipotecario o prendario minoritario en el marco de una votación de acuerdo de reorganización judicial, desea conservar sus derechos de ejecución que existen en situación de no concurso, y por tanto, desea resguardar sus probabilidades de pago, solamente posee como mecanismo de defensa solicitar al tribunal que conoce del concurso que declare que el bien sobre el que recae su garantía no es esencial para el giro de la empresa deudora (artículo 94 inciso 1 LREP). En caso de obtener una decisión favorable podrán enajenar separadamente el bien en garantía, debiendo su excedente ser destinado al cumplimiento del acuerdo (artículo 94 incisos 2 y 3 LREP). Las normas sobre efectos del acuerdo de reorganización judicial en las obligaciones garantizadas aplican al procedimiento de reorganización extrajudicial (artículo 113 LREP). Por tanto, un acreedor hipotecario o prendario minoritario, en el contexto de un procedimiento concursal de reorganización judicial o extrajudicial, que no logre obtener la declaración de no esencialidad del bien en garantía, verá frustrada sus expectativas de probabilidades de pago que posee en situaciones de no concurso. Así, se produce una afectación del derecho de tales acreedores que no existe en procedimientos concursales de liquidación. Más allá de que este escenario se presente habitual o no, el mismo da cuenta de la posibilidad de un escenario de forum shopping procedimental en materia concursal. En efecto, los incentivos se encuentran estructurados para que el deudor $\mathrm{B}^{*}$ pueda convencer a ciertos acreedores, sean valistas o privilegiados, para generar una disminución en las posibilidades de ejecución de acreedores privilegiados minoritarios $\mathrm{A}^{*}$, que posean garantías sobe bienes esenciales para su actividad, pero que no representen parte sustancial de su pasivo total. 


\section{LA EFICIENCIA Y EL PROBLEMA DEL FORUM SHOPPING PROCEDIMENTAL}

Una propuesta de solución planteada desde la eficiencia al problema del forum shopping es aquella sostenida por Rasmussen y Randall Thomas en su artículo Timing Matters: Promoting Forum Shopping By Insolvent Corporations $^{55}$. Para ellos el fenómeno del forum shopping no es objetable per se. Existirían ciertas eficiencias asociadas a la búsqueda del foro competencial y procedimental que mejor satisfaga los intereses de ciertos litigantes. Sin embargo, para que esas eficiencias puedan ser identificadas se necesita considerar el momento en que se realiza la elección del foro. Para ello, los autores distinguen dos momentos. El primero se realiza al momento en que se constituye la empresa. El segundo corresponde cuando se genera la situación de insolvencia ${ }^{56}$. La distinción de tales momentos se fundamenta en una serie de consideraciones. En efecto, el primer momento existe antes que la empresa comience la búsqueda de financiamiento para sus proyectos. Dentro de las condiciones se ofrecen a los potenciales inversionistas se encuentra la elección del foro que conocerá de una eventual insolvencia. A ello se pueden agregar cláusulas que limiten o restrinjan los comportamientos oportunistas del deudor cuando se acerque la situación de insolvencia. La racionalidad de la elección del foro en este momento se encuentra en el hecho que el deudor elegirá el foro que maximice su valor (maximize firm value). Lo anterior, porque solo una opción como aquella inducirá a terceros a financiar la empresa en cuestión. Asimismo, tal elección permite alinear los intereses de los administradores con los dueños de la empresa ya que ambos ganarán si es la compañía se valoriza por obtener financiamiento a bajo costo ${ }^{57}$.

Por contrapartida, el segundo momento existe cuando el concurso se acerca. En tal escenario los administradores del deudor son los que toman la decisión. Así, surge un problema de agencia donde los administradores no necesariamente perseguirán el interés de los dueños. Rasmussen y Thomas indican que los administradores elegirán el foro que maximice sus intereses personales, tales como, asegurar algún retorno en el concurso (con violación de la prioridad absoluta de los acreedores); mantenerse el mayor tiempo en sus cargos, y poder conservar poder de negociación en una reorganización. Tales beneficios corresponden a los intereses de la

55 Rasmussen, Robert y Thomas, Randall, Timing Matters: Promoting Forum Shopping By Insolvent Corporations, en Northwestern University Law Review 94 (1999-2000), pp. 1357-1408.

${ }^{56}$ Rasmussen, Robert y Thomas, Randall, cit. (n. 55), pp. 1358-1360.

57 Rasmussen, Robert y Thomas, Randall, cit. (n. 55), pp. 1382-1386. 
empresa ni de los acreedores, creando una distorsión asociado al fenómeno del forum shopping, que puede ser eliminada si se incentiva la elección del foro en el primer momento mencionado ${ }^{58}$.

La propuesta de Rasmussen y Thomas considera el problema que los tribunales concursales en el sistema norteamericano que han gozado de mayor popularidad para conocer grandes reorganizaciones son aquellos que han demostrado sistemáticamente un trato benigno a los deudores ${ }^{59}$. Por ello, los administradores cuando deciden el foro al cual someter el concurso tenderán a concurrir a esos tribunales ${ }^{60}$. Tal constatación si bien puede generar ciertas desventajas para el sistema (la elección del foro no es en función del tribunal que maximice el valor de las empresas), también produce eficiencias (se trata de tribunales que tienen manejo en grandes procedimientos de reorganización, por lo que su especialidad reduce los costos concursales). Con todo, existe una alternativa mejor. En este sentido, Rasmussen y Thomas señalan que incentivar el pacto del foro en el primer momento referido es lo que constituye la mejor opción de eficiencia para el sistema. De esta forma se selecciona la vía que maximiza el valor para la empresa, lo que elimina problemas de agencia, y además, tiende a la obtención de un financiamiento en mejores condiciones. Sistémicamente esa alternativa conducirá a que los tribunales generen precedente, en cuanto se los reconozca como órganos que mejoran el valor de las empresas en insolvencia. Si eso es así, se tenderá a optar por tales tribunales ${ }^{61}$.

Ahora bien, una propuesta como la de Rasmussen y Thomas supone un profundo compromiso con una administración de justicia que delega en los particulares importantes ámbitos de acción procesal. De hecho, la elección del foro queda completamente en manos de los particulares. Sin embargo, esa misma característica de fuerte privatización del sistema judicial concursal es en donde se demuestra la inaplicabilidad de la propuesta de esos autores al derecho procesal concursal chileno. En efecto, las normas de competencia de asuntos concursales se encuentran estructuradas como reglas de orden público no disponibles por las partes ex ante (artículo 3 LREP).

Una segunda propuesta de solución de eficiencia proviene de Richard Baird. Según este autor se requiere minimizar los costos que el forum shop-

58 Rasmussen, Robert y Thomas, Randall, cit. (n. 55), pp. 1396-1398.

59 Rasmussen, Robert y Thomas, Randall, cit. (n. 55), pp. 1371-1372.

${ }^{60}$ Esta es la explicación para la elección preferente durante la década de 1990, por los tribunales que ejercen competencia concursal en el Estado de Delaware; RAsMUSSEN, Robert y ThOMAs, Randall, cit. (n. 55), pp. 1368-1376.

${ }^{61}$ Rasmussen, Robert y Thomas, Randall, cit. (n. 55), pp. 1399-1406. 
ping impone a las partes ${ }^{62}$. Ello se consigue en la medida que el legislador no establezca reglas en el concurso que se diferencien de aquellas que existen en la ejecución individual de derecho común, a fin de no generar incentivos de sub-utilización o sobre-utilización del procedimiento concursal. La propuesta de Baird (compartida por Jackson ${ }^{63}$ ), se estructura para que las personas no tengan incentivos para favorecer una vía u otra, en razón de la búsqueda de fines de carácter distributivos. En este punto, se contraponen a la tesis de Warren ${ }^{64}$, para quien el proceso concursal debería tender a transformarse en un foro en donde las pérdidas sean distribuidas de forma que limiten el principio de prioridad absoluta de los acreedores. Así se aumentará la recuperación de los acreedores valistas con cargo a disminuciones correlativas en los acreedores privilegiados. Discutir las bondades y defectos de la prioridad absoluta de los acreedores escapa del foco de atención de este artículo ${ }^{65}$. Con todo, comparto con Baird y Jackson en cuanto a que no existen razones fuertes para generar una preocupación distributiva en el concurso que altere los órdenes de pago de la legislación común, siempre que tal preocupación distributiva de pérdidas se desentienda de la finalidad concursal ex post. Destinar los recursos escasos del concurso para favorecer cierta repartición de pérdidas de bienestar no se justifica cuando la finalidad del concurso es tratar de mejorar el estado de bienestar de la masa activa. La atención debe ser mejorar la tasa de recuperación, y no, generar favorecimientos cruzados entre acreedores.

No obstante lo anterior no significa que acepte la propuesta de Baird y Jackson. Al respecto, cuestiono su tratamiento minimización para afrontar la problemática del forum shopping. Al respecto, si minimizar los costos del forum shopping significa un igual tratamiento de la insolvencia y de las situaciones de no concurso, entonces, el argumento es contra-intuitivo. La legislación concursal surge para enfrentar en un escenario común la acción colectiva de los acreedores, bajo la premisa básica que en su ausencia, los acreedores no podrán coordinarse para mejorar su recupero. Sin embargo, el escenario concursal implica un costo, esto es, todas aquellas etapas e instrumentos procesales que diferencian el concurso de las ejecuciones individuales, y por las cuales, se busca mejorar la coordinación mencionada. Ejemplos de esos instrumentos, son la creación y funcionamiento de órganos concursales, la imposición de costos de publicación de ciertas actuaciones y resoluciones judiciales, la tramitación acumulativa de diversos

\footnotetext{
${ }^{62}$ Baird, Douglas, cit. (n. 10), p. 828.

${ }^{63}$ JACKSON, Thomas, cit. (n. 34), i, pp. 857-907.

${ }^{64}$ Warren, Elizabeth, cit. (n. 23), pp. 775-814.

${ }^{65}$ BebChuck, Lucian y Fried, Jesse, cit. (n. 22), pp. 2386-2436.
} 
procesos relacionados con el patrimonio concursado, la especialización de los jueces que conocen de estos asuntos, etc.

En la esencia misma del concurso, entonces, existe un aumento necesario de costos en comparación a la ejecución individual. Asimismo, concurre un costo asociado a las expectativas de cobro de los acreedores. En efecto, tales expectativas de cobro pueden ser de mayor o menor intensidad. Así, en el proceso concursal de liquidación la expectativa de los acreedores con garantía real se ve afectada solo en la necesidad de pago previo a los acreedores que poseen créditos contra la masa; en cambio, en la reorganización tal expectativa se vulnera siempre que esos acreedores sean minoritarios respecto de un plan de reorganización que altere su derecho de persecución independiente. En todo caso, esas expectativas serán afectadas a un costo, el que será asumido por aquellos acreedores que en situación de no concurso deberían ser inmunes a externalidades negativas de terceros (deudor y acreedores ordinarios). Asimismo, partes de esos costes, serán asumidos por un procedimiento más caro y lento en comparación con la ejecución individual. Con todo, los costos del error concursal se reducen con un aumento en los costos administrativos vía especialización. Dada la existencia de tales costos no es posible un tratamiento idéntico a los acreedores en la legislación concursal y en la común.

Los problemas de coordinación que impone la acción colectiva de los acreedores requiere de un tratamiento diferenciado. Como consecuencia, una idea de minimización de costos no resulta intuitivamente correcta ni jurídica y económicamente aceptable. Al respecto, me parece que un tratamiento de optimización resulta más adecuado. Las diferenciaciones entre la legislación concursal y común al abordar la incapacidad de pago de un deudor con varios acreedores debe ponderar, por un lado, la necesidad de un aumento de costos para implementar una vía resuelva tal diferenciación, y por otro, los costos marginales que esos incrementos producen.

Tal solución no implica la mínima diferenciación posible entre el concurso y la ejecución individual, sino que, asumiendo un mayor costo de lo que sucede en la propuesta de minimización, se traduzca en una norma que asigne esos costes en quienes decidan generarlos. Así, el aumento del bienestar producido por la solución del problema de acción colectiva se verá justificado por el aumento de los desembolsos necesario para que tal incremento de bienestar se genere. Interesante es constatar que Baird y Jackson parecen finalmente sostener un tratamiento de ponderación de costos y no de minimización. Me refiero a la propuesta que han realizado en su artículo Corporate Reorganizations and the Treatment of Diverse Ownership Interests: A Comment on Adequate Protection of Secured Creditors 
in Bankruptcy ${ }^{66}$. Allí señalan que en ciertos supuestos una reorganización en el capítulo 11 del Bankruptcy Code, resulta aceptable cuando los costos que impone en los acreedores privilegiados son compensados por el riesgo que asumen los valistas de no ser exitosa la reorganización. En concreto, los valistas deben pagar al acreedor privilegiado un excedente en el caso de tal éxito, como una especie de contraprestación por el riesgo asumido por los privilegiados en la reorganización ${ }^{67}$. Esta última aproximación me parece coherente con un tratamiento de óptimo del fenómeno del forum shopping. Tal solución debe concretizarse en una propuesta normativa, la que será examinada en un trabajo futuro. Por ahora lo importante es el diagnóstico: el fenómeno del forum shopping en materia de acción colectiva de los acreedores no es per se negativo, simplemente requiere una ponderación óptima de intereses.

\section{CONCLUSIONES}

Se sostiene que no existe un estado de cosas de déficit patrimonial o financiero que de origen a un e s t a d o c o n c u r s a l, de forma que la ley no configura una solución única frente a la existencia de la incapacidad de pago del deudor. La tutela individual y colectiva son vías disponibles cuya elección dependerá de los incentivos normativos. En ese contexto, el derecho concursal chileno en materia de acción colectiva de los acreedores es un terreno fértil para el fenómeno del forum shopping procedimental. Se ha visto que en la generalidad de los casos los incentivos de deudores y acreedores están tratados por la legislación de manera interrelacionada. Tal escenario permite configurar supuestos de dominancia de alternativas (estrictas y débiles), que significan que la legislación entrega a esos sujetos la opción de elegir una opción que dominará (estricta o débilmente) a su alternativa, dependiendo de cómo y cuándo elijan jugar sus oponentes. La

${ }^{66}$ BAIrd, Douglas y JaCKSOn, Thomas, cit. (n. 1), vi.

${ }^{67}$ De acuerdo a BAIRD, Douglas y JACKSON, Thomas, cit. (n. 1), vi , p. 125, tal propuesta se basa en que: "A rule that foreces general creditors and shareholders to give secured creditors the full value of their claims (including compensation for the time value of money) puts the cost of a decision to reorganize the firm entirely on the junior clases, who already stand to benefit if the firm succeeds. As a consequence, they have incentives that approximate those of a sole owner". (Trad. del autor: "Una regla que obliga a los acreedores generales y a los accionistas a dar a los acreedores garantizados el valor total de sus demandas (incluyendo la compensación por el valor de tiempo del dinero) pone el costo de una decisión de reorganizar la empresa enteramente en las manos de las clases valistas, quienes se beneficiarán si la firma es reorganizada exitosamente. Como consecuencia, ellos tienen incentivos que se aproximan a los de un único dueño"). 
solución vendrá dada por aquel compromiso regulatorio que significando un mayor costo en comparación con la alternativa de minimización, se traduzca en una norma que asigne los costos en quienes deciden generarlos.

\section{BibLIOGRAFíA}

Aghion, Philippe; Hart, Oliver; Moore, John, Improving Bankruptcy Procedures, en Washington University Law Review, 72 (1994) 3.

Algero, Mary, In Defense of Forum Shopping: A Realistic Look at Selecting a Venue, en Nebraska Law Review 78 (1999) 1, pp. 79-112.

Altman, Edward, A Further Empirical Investigation of the Bankruptcy Cost Question, en The Journal of Finance XXXIX (1984) 4, pp. 1067-1089.

Atria, Fernando, Creación y aplicación del derecho: Entre formalismo y escepticismo, en Atria, Fernando; Bulygin, Eugenio; Moreso, Juan José; Navarro, Pablo; Rodríguez, Jorge; Ruiz Manero, Juan, Lagunas en el Derecho (Madrid, Marcial Pons, 2005).

Atria, Fernando, Réplica: Entre jueces y activistas disfrazados de jueces, en ATRIA, Fernando; Bulygin, Eugenio; Moreso, Juan José; Navarro, Pablo; Rodríguez, Jorge; Ruiz Manero, Juan, Lagunas en el Derecho (Madrid, Marcial Pons, 2005).

BAIRD, Douglas, Loss Distribution, Forum Shopping, and Bankruptcy: A Reply to Warren, en The University of Chicago Law Review 54 (1987), pp. 815 -834.

BAIRD, Douglas y JACKSON, Thomas, Corporate Reorganization and the Treatment of Diverse Ownership Interests: A Comment on Adequate Protection of Secured Creditors in Bankruptcy, en University of Chicago Law Review 51 (1984), pp. 97-130.

Bassett, Debra, The Forum Game, en North Carolina Law Review 84 (2006), pp. 267-334.

BAYÓN, Juan Carlos, Eficiencia e inalienabilidad, en Doxa, Cuadernos de Filosofía del Derecho II (1994) 15, pp. 971 - 991.

BAXTER, William, Choice of Law and the Federal System, en Stanford Law Review 16 (1963) 1, pp. 1-42.

Blazy, Regis y Chopard, Bertrand, Ex-post Efficiency and Bankruptcy Procedure: A General Normative Approach, en International Review of Law and Economics 24 (2004) 4, pp. 447-471.

BEBCHUCK, Lucian, Ex ante costs of violating absolute priority in bankruptcy, en Discussion Paper Harvard Law School 328 (2011).

Bebchuck, Lucian y Fried, Jesse, A New Approach to Valuing Secured Claim in Bankruptcy, en Harvad Law Review 114 (2011), pp. 2386-2436.

Berkovitch, Elazar y IsRael, Ronen, The bankruptcy decisión and debt contract renegotiation, en Review of Finance 2 (1998) 1, pp. 1-27.

BEYER, Harald, Ronald Coase y su contribución a la teoría de la economía y del derecho, en Revista de Estudios Públicos 45 (1992), pp. 1-21.

Bisogno, Marco y De LuCA, Roberto, Bankruptcy Effiency and Indirect Cost in Italian SMEs: a Temporal Approach, en International Journal of Business Research and Development 3 (2014) 2, pp. 12 - 27.

Bofill, Octavio y ARAYA, Ignacio, Análisis y comentarios a la reforma al régimen concursal chileno, en Revista de Derecho. Escuela de Postgrado Universidad de Chile 4 (2013), pp. $281-324$. 
Bradley, Michael, The Untenable Case for Chapter 11, en Yale Law Journal 101 (1992) 5, pp. 1043-1095.

Brealey, Stewart y Myers, Franklin, Principles of Corporate Finance ( $2^{a}$ edición, New York, McGraw-Hill, 1984).

Bullow, Jeremy y Shoven, John, The Bankruptcy Decision, en The Bell Journal of Economics 9 (1978) 2, pp. 437 - 456.

Bulygin, Eugenio, Creación y aplicación del Derecho, en Atria, Fernando; Bulygin, Eugenio; Moreso, Juan José; Navarro, Pablo; Rodríguez, Jorge; Ruiz Manero, JuAn, Lagunas en el Derecho (Madrid, Marcial Pons, 2005).

Cabrillo, Francisco, Quiebra y liquidación de empresas, (1 $1^{\text {a }}$ edición, Madrid, Unión Editorial, 1989).

CAlabresi, Guido, El coste de los Accidentes: análisis económico y jurídico de la responsabilidad civil (traducción de Joaquim Bisbal, Barcelona, Editorial Ariel, 1984).

Carapeto, Maria, Is bargaing in Chapter 11 costly?, en Working Paper, London City University Business School (2000), pp. 1-46.

Carrasco, Nicolás y Nuñez, Raúl, Conceptos generales del Análisis Económico del Derecho Concursal, en CARRASCO, Nicolás y NúNEZ, Raúl (coordinadores), Presente y Futuro del Derecho Procesal Concursal Chileno. Una revisión desde el Análisis Económico del Derecho (Santiago, Editorial LegalPublishing, 2014), pp. 3-88.

Chemerinsky, Erwin, Assessing Minimum Contacts: A Reply to Professors Cameron and Johnson, en UC Davis Law Review 28 (1995), pp. 863-870.

Chen, G.M. y Merville, Larry, An analysis of the underreported magnitude of the total costs of financial distress, en Review of Quantitative Finance and Accounting 13 (1999) 3, pp. $277-293$.

Clermont, Kevin, Restating Territorial Jurisdiction and Venue for State and Federal Courts, en Cornell Law Review 66 (1981) 3, pp. 411-463.

Clermont, Kevin y Eisenberg, Theodore, Exorcising the Evil of Forum-Shopping, en Cornell Law Review 80 (1995) 6, pp. 1507-1535.

COASE, Ronald, El problema del costo social, en Revista de Estudios Públicos 45 (1992), pp. $81-134$.

Concha, Carlos, El Proceso de Quiebras (Valparaíso, Editorial López Vivanco, 1971).

Cooter, Robert y Ulen, Thomas, Derecho y Economía (5a edición, México, Fondo de Cultura Económica, 1998).

Correa, Jorge; Peña, Carlos; Vargas, Juan Enrique, ¿Es la justicia un bien público?, en Revista Perspectivas, Departamento de Ingeniería Industrial - Universidad de Chile 3 (2000) 2, pp. $389-409$.

CORR, John, Thoughts on the Vitality of Erie, en The American University Law Review 41 (1992), pp. 1087-1137.

Cossio, José Ramón, Derecho y análisis económico (México, Fondo de Cultura Económico, 1997).

Currivan, John, Choice of Law in Federal Court After Transfer of Venue, en Cornell Law Review 63 (1977) 1, pp. 149-163.

Cutler, David y Summers, Lawrance, The Costs of Conflict Resolution and Financial Distress: Evidence from the Texaco-Pennzoil Litigation, en Rand Journal of Economis 19 (1987) 2, pp. $157-172$.

Durán, Paloma, Una aproximación al análisis económico del Derecho (Granada, Comares, 1992).

EGER, Thomas, Bankruptcy Regulations and the New German Insolvency Law from 
an Economic Point of View [visible en internet: http://www.researchgare.net/ publication/5145554].

FAULK, Richard, Armaggeddon Through Agregation? The use and abuse of class actions in international dispute resolution, en Tort and Insurance Law Journal 37 (2002), pp. 999 - 1026.

FERRARI, Franco, Forum Shopping in the International Commercial Arbitration Context: Setting the Stage, en FerRARI, Franco (Editor), Forum Shopping in the International Commercial Arbitration Context (New York, Sellier European Law Publishers, 2013), pp. 1-22.

FrISBY, Sandra, Report on Insolveny Outcomes, en The Insolvency Service Report (2006), pp. $32-44$.

García, Miguel y Mora, Juan, El uso de los concursos de acreedores en España, en Boletín Económico. Banco de España (2012), pp. 27 - 38.

GOLDENBERG, Juan Luis, Los acuerdos extrajudiciales desde la visión privatista del derecho concursal, en Revista de Derecho de la Pontificia Universidad Católica de Valparaíso 42 (2014), pp. 187 - 223.

González, Víctor Manuel y González, Francisco, Procedimientos de resolución de insolvencia financiera en España: Costes de insolvencia y trasferencias de riqueza, en Investigaciones Económicas XXIV (2000) 2, pp. 357 - 384.

Hart, Oliver, Different approaches to Bankruptcy, en National Bureu of Economic Research (2000) [visible en internet: http://www.nber.org/papers/w7921].

HART, Oliver, Firms, Contract and Financial Structure (1 ${ }^{\mathrm{a}}$ edición, Oxford, Claredon Press, 1995).

Hart, Herbert, El concepto de Derecho (traducción de Genaro Carrió, Buenos Aires, Abeledo-Perrot, 1963).

Hicks, John, The Foundations of Welfare Economics, en The Economic Journal 49 (1939) 196, pp. 696 - 712.

Hicks, John, The Rehabilitation of Consumers'Surplus, en Review of Economic Studies 8 (1941), pp. 108 - 116.

Hierro, Liborio, Justicia, igualdad y eficiencia (Madrid, Centro de Estudios Políticos y Constitucionales, 2002).

Hylton, Keith, Calabresi and the intellectual history of Law \& Economics, en Boston University School of Law Working Paper N o 04-04 [visible en internet: http:// papers.ssrn.com/sol3/papers.cfm?abstract_id=547082].

JACKSON, Thomas, Bankruptcy, Non-Bankruptcy Entitlements, and the Creditors' Bargain, en The Yale Law Journal 91 (1982) 5, pp. 857 - 907.

JACKSOn, Thomas, The Logic and Limits of Bankruptcy Law, en Discussion Paper Program in Law and Economics Harvard Law School, 16 (1985) 1 - 122.

JACKSON, Thomas, The logic and Limits of Bankruptcy Law (Cambridge, Harvard University Press, 1986).

KALDOR, Nicholas, Welfare Propositions of Economics and Interpersonal Comparisons of Utility, en The Economic Journal 49 (1939) 195, pp. 549 - 552.

LoPucki, Lynn y Whitford, William, Venue Choice and Forum Shopping in the Bankruptcy Reorganization of Large, Publicly Held Companies, en Wisconsin Law Review 11 (1991), pp. 11-63.

Longhofer, Stanley y Peters, Stephen, Protection for whom? Creditor conflict and Bankruptcy, en American Law and Economic Review 6 (2004) 2, pp. 249 - 284. 
Lundquist, Weyman, The New Art of Forum Shopping, en Litigation, 11 (1985) 3, pp. 21-59.

MaIER, Harold y Mccoy, Thomas, A Unifying Theory for Judicial Jurisdiction and Choice of Law, en The American Journal of Comparative Law 39 (1991) 2, pp. 249-292.

Marcus, Richard, Conflicts Among Circuits and Transfers Within the Federal Judicial System, en The Yale Law Journal 93 (1984), pp. 677-721.

Marinc, Matej y Vlahu, Razvan, The Economics of Bank Bankruptcy Law, (Heidelberg, Springer, 2012).

Mendonca, Daniel, Errores Judiciales, en Cuadernos de derecho público 4 (mayo-agosto 1998), pp. 199 - 206.

MerCado, Pedro, El análisis económico del derecho. Una reconstrucción teórica (Madrid, Centro de Estudios Políticos y Constitucionales, 1994).

Mooney, Charles, A Normative Theory of Bankruptcy Law: Bankruptcy As (Is) Civil Procedure, en Faculty Scholarship, Paper 18 [visible en internet: http://scholarship. law.upenn.edu/faculty_scholarship/18].

Norwood, Kimberly, Shopping for a Venue: The Need for More Limits on Choice, en University of Miami Law Review 50 (1996), pp. 267-334.

Pareto, Vilfredo, Manual de Economía Politica (traducción de Guillermo Cabanellas, Buenos Aires, Editorial Atalaya, 1954).

PARETO, Vilfredo, Escritos sociológicos (traducción de María Luz Morán, Madrid, Editorial Alianza, 1987).

Pérez Ragone, Álvaro, Prelación, isonomía y agrupamiento de créditos en la ejecución civil, en Revista de Derecho de la Pontificia Universidad Católica de Valparaíso XXXVII (2011), pp. 437 - 479.

Posner, Richard, El análisis económico del Derecho (1 $1^{\mathrm{a}}$ edición, México, DF, Fondo de Cultura Económica, 1992).

Posner, Richard, Some uses and Abuses of Economics in Law, en The University of Chicago Law Review 46 (1979) 2.

Povel, Paul, Optimal Soft or Toigh Bankruptcy Procedures, en The Journal of Law, Economics and Organization 15 (1999) 3, pp. 659 - 684.

Pulvino, Todd, Do asset fire-sale exist? An empirical investigation of comercial aircraft transactions, en Journal of Finance 53 (1998), pp. 939 - 978.

Ramseyer, Mark, Not-so-Ordinary Judges in Ordinary Courts: Teaching Jordan vs. Duff \& Phelps, Inc, en Harvard Law Review 120 (2007), pp. 1199 -1209.

Rasmussen, Robert, Ex Ante Effects of Bankruptcy Reform, en Washington University Law Quarterly 72 (1994) 3, pp. 1159 - 1211.

Rasmussen, Robert y Thomas, Randall, Timing Matters: Promoting Forum Shopping By Insolvent Corporations, en Northwestern University Law Review, 94 (1999-2000), pp. $1357-1373$.

RHODES-KROPF y VisWANATHAN, S., Corporate reorganizations and non-cash auctions, en Journal of Finance 55 (2000) 4, pp. 1807 - 1849.

Roemer, Andrés, Introducción al análisis económico del derecho (México, Fondo de Cultura Económica, 1994).

ShleIfer, Andrei y Vishny, Robert, Liquidation values and debt capacity: A market equilibrium approach, en Journal of Finance 47 (2012) 4, pp. 1343-1366.

Scitovsky, Tibor, A note on Welfare Propositions in Economics, en Review of Economics Studies 9 (1941), pp. 77-88.

SMITH, David y STRÖMBERT, Per, Maximizing the Value of Distressed Assets: Bankruptcy 
the Efficient Reorganization of Firms, [visible en internet: http://www1.worldbank. org/finance/assets/images/Smith-Stromberg_Maximizing.pdf].

Simowitz, Aaron, A U.S Perspective on Forum Shopping, Ethical Obligations, and International Commercial Arbitration, en FerRari, Franco (Editor), Forum Shopping in the International Commercial Arbitration Context (New York, Sellier European Law Publishers, 2013), pp. 23-52.

STERnBERG, Daniel, Res Judicata and Forum Non Conveniens in International Litigation, en Cornell International Law Journal 46 (2003), pp. 191-218.

Sugden, Robert, Spontaneous Order, en Journal of Economic Perspectives, 3 (1989) 4, pp. 85-97.

Veljanovski, Cento, Economía del Derecho (traducción de Iñigo de la Maza, y Rafael Mery, Santiago, Ediciones Diego Portales, 2006).

Warren, Elizabeth, Bankruptcy Policy in an Imperfect World, en Michigan Law Review 92 (1993) 2, pp. $336-387$.

Warren, Elizabeth, Bankruptcy Policy, en The University of Chicago Law Review 54 (1987) 3, pp. 775-814.

WARnER, Jerold. Bankruptcy Costs: Some Evidence, en The Journal of Finance XXXII (1977) 2, pp. 337 - 347.

WHITE, Michelle, Bankruptcy Costs and the New Bankruptcy Code, en Journal of Finance 38 (1983) 2, pp. 477 - 488.

WohlsChlegel, Ansgar, The Economics of Corporate Bankruptcy Law [visible en internet: archiv.ub.uniheidelberg.de/savifadok/volltexte/.../Diss_Wohlschlegel.pdf].

ZiPITRÍA, Leandro, Un análisis económico-institucional de los procedimientos concursales en el Uruguay (Facultad de Ciencias Económicas y de Administración, Universidad de la República Oriental de Uruguay, 2000). 
